\title{
Imaging of sarcoidosis of the airways and lung parenchyma and correlation with lung
} function

\author{
Hilario Nunes*, Yurdagul Uzunhan*, Thomas Gille", Christine Lamberto", \\ Dominique Valeyre* and Pierre-Yves Brillet
}

ABSTRACT: Imaging has a prominent role in the assessment of sarcoidosis diagnosis and outcome, which are extremely variable. Chest radiography staging helps predict the probability of spontaneous remission, and stage IV is associated with higher mortality. However, the reproducibility of reading is poor and changes in radiography and lung function are inconsistently correlated, which may be problematic for the monitoring of disease and treatment response. Chest computed tomography (CT) makes a great diagnostic contribution in difficult cases. Bilateral hilar lymphadenopathy with peri-lymphatic micronodular pattern is highly specific for sarcoidosis. CT is important for the investigation of pulmonary complications, including aspergilloma and pulmonary hypertension. CT improves the yield of bronchoscopy for obtaining a positive endobronchial or transbronchial biopsy. CT findings may also discriminate between active inflammation and irreversible fibrosis, with occasional influence on therapeutic decisions. Three CT patterns of fibrotic sarcoidosis are identified, with different functional profiles: predominant bronchial distortion is associated with obstruction; honeycombing is associated with restriction and lower diffusing capacity of the lung for carbon monoxide; whereas functional impairment is relatively minor with linear pattern. The clinical impact of correlations between CT severity scores and functional impairment is uncertain, except for its utility elucidating the mechanisms of airflow limitation, which include bronchial distortion, peribronchovascular thickening, air-trapping and bronchial compression by lymphadenopathy.

KEYWORDS: Chest radiography, computed tomography, diagnosis, outcome, pulmonary function testing, sarcoidosis

arcoidosis is a systemic granulomatous disease of unknown cause that primarily affects the lungs and the lymphatic system (in more than $90 \%$ of patients). Disease clinical phenotypes, course and prognosis are highly heterogeneous. The diagnosis of sarcoidosis is based upon the association of compatible clinical and radiological findings, histological demonstration of noncaseating granulomas, and exclusion of other granulomatous disorders [1]. However, clinical and radiological findings are extraordinarily variable and histological confirmation is sometimes elusive. The value of chest radiography for the diagnosis of sarcoidosis is unsatisfactory. Chest computed tomography (CT) is much more accurate, but it is not required in all patients. Its true role has been delineated more clearly in cases with difficult diagnosis or suspected pulmonary complications. Imaging also makes a major contribution to the appraisal of prognosis. The radiography staging described by SCADDING [2] more than five decades ago continues to hold a prominent position in the assessment of sarcoidosis outcome, although drawbacks in the reproducibility of reading have recently been underlined. Similarly, the role of radiography versus pulmonary function tests (PFTs) in the

Previous articles in this series: No. 1: Schlobin OA, Nathan SD. Management of end-stage sarcoidosis: pulmonary hypertension and lung transplantation. Eur Respir J 2012; 39: 1521-1534. No. 2: Drent M, Lower EE, De Vries J. Sarcoidosis-associated fatigue. Eur Respir J 2012; 40: 255-263.

\section{AFFILIATIONS}

*Dept of Pneumology, University of Paris 13, UPRES EA 2363

Assistance Publique-Hôpitaux de Paris, Avicenne Hospital, Bobigny, ${ }^{*}$ Dept of Physiology, University of Paris 13, UPRES EA 2363, Assistance Publique-Hôpitaux de Paris, Avicenne Hospital, Bobigny, and

"Dept of Radiology, University of Paris 13, UPRES EA 2363,

Assistance Publique-Hôpitaux de Paris, Avicenne Hospital, Bobigny, France.

\section{CORRESPONDENCE}

Hilario Nunes

Service de Pneumologie

Hôpital Universitaire Avicenne

125 rue de Stalingrad

93009 Bobigny

France

E-mail: hilario.nunes@avc.aphp.fr

Received:

Feb 102012

Accepted after revision:

June 112012

First published online:

July 122012 
monitoring of disease against has been the subject of controversy. Numerous studies have correlated CT features with disease activity and CT scores with functional abnormalities, essentially in an attempt to better understand the mechanisms of complications such as airflow limitation. It is important to evaluate the clinical impact of these correlations between imaging and PFTs. In fact, there is a lack of consensus concerning the best end-point for the monitoring of disease and treatment response, which is critical in clinical trials.

In this article, we review current knowledge and emerging concepts in the imaging of pulmonary sarcoidosis with parenchymal and/or airway involvement, with a particular focus on the correlation with lung function. We will not deal with positron emission-computed tomography (PET-CT), a technique that may have a prominent place in the near future, because it is the topic of another article in this series.

\section{CHEST RADIOGRAPHY}

Conventional chest radiography should be performed in all sarcoidosis patients. It is abnormal in some way in more than $90 \%$ of cases and is often the first investigation to suggest the diagnosis $[1,3,4]$. Between $30-60 \%$ of patients present with incidental radiographic abnormalities [4].

\section{Radiographic features}

The most salient feature of sarcoidosis is bilateral hilar lymphadenopathy (BHL), noted in $50-80 \%$ of cases, which is typically symmetrical and noncompressive $[4,5]$. In patients with thoracic lymphadenopathy, BHL is present in over $95 \%$ of cases, often associated with enlargement of right paratracheal and aortic-pulmonic window lymph nodes (more than $70 \%$ of cases with thoracic lymphadenopathy). Subcarinal (21\%), anterior mediastinal (16\%) and posterior mediastinal (2\%) involvement are less frequent [6]. The presence of lone paratracheal, subcarinal or mediastinal enlarged lymph nodes without BHL is exceptional [6], as is unilateral hilar lymphadenopathy, and should raise the possibility of an alternative diagnosis (i.e. infection including tuberculosis or histoplasmosis, lymphoma, or bronchogenic or extra-thoracic carcinoma). Nodal size ranges from minimal to massive and tends to be largest at presentation, with gradual diminution leading, in a majority of cases, to complete regression within 2 years. When initially unilateral, sarcoidosis lymph nodes usually become bilateral within 3 months. In long-standing sarcoidosis, calcification is seen on chest radiography in more than $20 \%$ of cases after 10 years of disease, appearing in most instances during the second or third decade after onset [7].

Pulmonary infiltrates are noted in $25-50 \%$ of sarcoidosis patients $[4,5]$. Infiltrates are usually bilateral and symmetrical with a frank predilection for mid/upper lung zones. The pattern is typically micronodular or reticulomicronodular $[4,5]$. When present, pulmonary fibrotic changes are variably marked on chest radiography with evidence of architectural distortion, upper lobe volume loss with hilar upward retraction, coarse linear bands, masses, and bullae in advanced disease $[4,5]$.

Radiographic findings are atypical in approximately $20 \%$ of cases $[8,9]$ and are more frequent in patients over the age of 50 yrs [10]. CT is of considerable aid when radiographic presentation is atypical and not immediately diagnostic, as discussed later in this article.

\section{Radiographic scoring systems}

\section{Scadding staging}

SCADDING [2] classified postero-anterior chest radiography findings in sarcoidosis into five stages: stage 0 (normal); stage I (BHL); stage II (BHL accompanied by pulmonary infiltrates); stage III (pulmonary infiltrates without BHL); and stage IV (overt pulmonary fibrosis). The distribution of patients according to radiographic stages largely depends on geographic or ethnic origin and referral source. Overall, the frequency of each stage at presentation is reported as: stage 0, 5-15\%; stage I, 25$65 \%$; stage II, $20-40 \%$; stage III, $10-15 \%$; and stage IV, approximately $5 \%$ (table 1 ) [1, 3-5].

A major shortcoming with this staging classification is the poor reproducibility of reading. In a recent study, the overall agreement between two expert radiologists was fair (weighted $\kappa=0.43$ ). The two major problems of interpretation were the assessment of lymphadenopathy and the presence of fibrosis [11]. Surprisingly, the interobserver agreement was quite good in another study (weighted $\kappa>0.8$ ), including for the adjudication of stage IV disease [12].

\section{Muers scoring system}

The International Labor Organization (ILO) radiographic scoring system, originally developed for pneumoconiosis, has been modified and applied to sarcoidosis. In this system, shadows are categorised into four subtypes (R: reticulonodular; M: mass; C: confluent; or F: fibrosis), which are assigned a score based on extent and profusion separately [13]. Interobserver agreement is better than that of Scadding staging, with weighted $\kappa$ values ranging from $0.327-0.578$ in one study [11] and $0.67-0.87$ in another [13], depending on the type of score. $\mathrm{R}$ is the predominant abnormality, with a strong correlation between extent and profusion components [13] and the best agreement between readers $[11,13]$.

\section{Role of chest radiography in the diagnosis of sarcoidosis}

In the absence of pathological confirmation, clinical and/or radiographic features may be diagnostic in stage I (reliability of $98 \%)$ or stage II $(89 \%)$ sarcoidosis, but are less accurate for patients with stage III $(52 \%)$ or stage $0(23 \%)$ disease [1]. Other important causes of BHL, all much less frequent than sarcoidosis, are infection (mycobacterial or fungal) and malignancy (lymphoma, bronchogenic or extra-thoracic carcinoma). In a

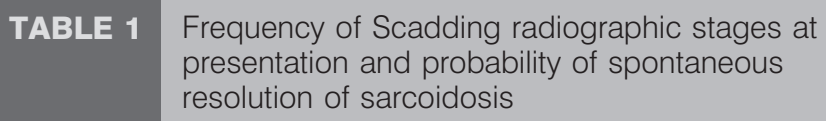

0 
large series, WINTERBAUER et al. [14] revealed that symmetrical BHL was the mode of presentation in only $3.8 \%$ of lymphomas, $0.8 \%$ of bronchogenic carcinomas and $0.2 \%$ of extra-thoracic carcinomas [14]. Asymptomatic BHL, in association with an unremarkable physical examination or acute symptoms (i.e. uveitis, polyarthritis or erythema nodosum), was highly suggestive of sarcoidosis. Conversely, BHL indicated malignancy when associated with anaemia, a pleural effusion or anterior mediastinal mass, peripheral lymphadenopathy or hepatosplenomegaly [14]. Thus, pathological verification can reasonably be skipped in many patients with typical stage I disease, provided that they are asymptomatic or have Löfgren's syndrome [1].

\section{Role of chest radiography in the prognosis of sarcoidosis}

\section{Radiographic staging and disease outcome}

Despite its purely descriptive nature, Scadding radiographic staging supplies major prognostic information. Although individual exceptions exist, there is clearly an inverse relationship between stage at presentation and the probability of recovery from sarcoidosis. Spontaneous resolution occurs in $60-90 \%$ of patients with stage I disease, $40-70 \%$ of those with stage II and $10-20 \%$ of those with stage III and does not occur with stage IV disease (table 1) [1, 4,5]. Regardless of the initial stage, the majority of spontaneous remissions occur within the first 2 years after presentation. The likelihood of remission is reduced after 5 years, but patients do not necessarily show a stepwise progression from stage 0 to stage IV disease. In a large patient cohort, only $9 \%$ of stage I patients had progressed to stage II (and $1.6 \%$ to stages III or IV) at 5 years, while only $5.5 \%$ of stage II patients had progressed to stage IV [15]. Stage I disease persists after 5 years in $8 \%$ of cases, which is not inevitably a sign of ongoing activity. Stage IV usually develops after 5 or more years of disease. It is associated with substantial morbidity and higher mortality [16, 17].

\section{Correlations of chest radiography with baseline lung function}

In individual cases, radiographic findings do not, in themselves, discriminate reliably between active inflammation and fibrosis. Moreover, correlations between radiographic staging and other pulmonary parameters such as the degree of physiological impairment, dyspnoea [18] and 6-min walk test [19] are imprecise. Overall, PFTs are abnormal in about $20 \%$ of patients with stage I disease, and $40-80 \%$ of those with pulmonary infiltrates (stage II, III or IV) $[3,4,20]$. The frequency and severity of restrictive defect and reduced diffusing capacity of the lung for carbon monoxide $(D \mathrm{~L}, \mathrm{CO})$ usually increase in more advanced stages. However, even when chest radiography is normal, alterations in forced vital capacity (FVC) and DL,CO are noted in 15-25\% and $25-50 \%$ of cases, respectively [4, 20]. Although occurring at all stages of disease, airflow limitation is more frequent with progressive staging: reported frequencies of airflow limitation are: $2-25 \%$ in stage $0 ; 7-12 \%$ in stage I; $8-38 \%$ in stage II; $10-23 \%$ in stage III; and $45-71 \%$ en stage IV [21-23]. Stage IV disease has been found to be an independent index that relates to lower forced expiratory volume in $1 \mathrm{~s}$ (FEV1)/FVC in a large prospective study [22] and some patients with stage IV exhibit severe obstructive defects [24, 25].

Exercise gas exchange measurements vary significantly with radiographic stage $[26,27]$. However, resting $D \mathrm{~L}, \mathrm{CO}$ has a much superior performance than chest radiography in predicting exercise-induced desaturation [26, 27]. Arterial desaturation is usually not observed in stage 0-I disease [27]. In patients with stage II-IV disease, there is no further independent improvement in variable prediction when radiographic staging is considered in addition to DL,CO [27]. In one study, radiographic stage was found to be more significantly associated with alveolar-arterial oxygen tension difference $\left(P(A-a), \mathrm{O}_{2}\right)$ than with $D$ L,CO in patients with stage $0-$ II disease [26]. Semi-quantitative chest radiography scoring systems improve the correlations with baseline physiological impairment [13] and changes during follow-up (discussed later in this article).

\section{Role of chest radiography in the monitoring of sarcoidosis}

Correlations between changes in serial chest radiographs and lung function

Chest radiography is inexpensive, noninvasive and easily accessible. Together with serial PFTs, it is traditionally considered the cornerstone of monitoring of sarcoidosis patients [1]. However, there are few data to validate this role of radiography.

In a prospective study of long-term corticosteroids in pulmonary sarcoidosis, changes in chest radiography were analysed against physiological parameters over 5 years. Significant correlations were demonstrated with $\mathrm{R}$ and $\mathrm{F}$ scores on the Muers scoring system. Despite low correlation coefficients, $\mathrm{R}$ score improved in parallel with spirometry and $\mathrm{DL}, \mathrm{CO}$ and a worsening F score was associated with deteriorating FEV1 and DL,CO [13]. Similarly, BAUGHMAN et al. [11] evaluated the sensitivity of chest radiography to detect treatment effect in the prospective trial of infliximab for pulmonary sarcoidosis [11]. The films were compared using two methods: the Muers scoring system and the five-point Likert scale global assessment of change (markedly worsened, worsened, unchanged, improved, and markedly improved). Interobserver agreement was good for the two methods (weighted $\kappa=0.61$ for the Likert scale). Only the R score showed a significant improvement with therapy. The initial $\mathrm{R}$ score was positively correlated with subsequent improvement in FVC under therapy. There was also a significant correlation between the changes in FVC and both the changes in R score and the global assessment. Correlation was better for the latter [11], suggesting that the evaluation of a simple instrument, easily applicable in routine, was at least as robust as the complex Muers scoring system.

In a large retrospective study, ZAPPALA et al. [12] also examined two methods of serial chest radiographic scoring in relation to serial pulmonary function trends, irrespective of treatment effect [12]. Changes in Scadding radiographic stage and disease extent were condensed into a three-point scale: reduction, stability and increase. Despite fair to good interobserver agreement for each of the two methods (weighted $\kappa>0.76$ for the change in disease extent), the relationship between changes in stage and disease extent at 2 and 4 years of follow-up was poor. Changes in disease extent were linked to FEV1, FVC and DL,CO variations, whereas changes in stage were not. However, discordance between PFTs and disease extent data was still observed in approximately $50 \%$ of cases. In the remaining cases, isolated change in disease extent was more frequent than isolated change in PFTs, but in 6\%, disease extent and PFTs exhibited change in opposing directions [12]. 
The utility of chest radiography in diagnosing exacerbations of pulmonary sarcoidosis was addressed by JUDSON et al. [28], using the profusion score of the ILO reading system. Exacerbation was defined by worsening pulmonary symptoms thought to be related to pulmonary sarcoidosis (i.e. not infection) that responded to an increase of the corticosteroid dose. A subset of these patients $(66.7 \%)$ was identified with a spirometric decline of $\geqslant 10 \%$ in FVC or FEV1 from the previous baseline visit. Interobserver agreement in the determination of profusion score appeared to be moderate (weighted $\kappa=0.54$ ). Although changes in profusion score tended to worsen during exacerbations in both the whole population and the spirometric decline subgroup, a large percentage of readings demonstrated no modification (32\% and $27 \%$, respectively) or an improvement (19\% and 23\%, respectively). As expected, a significant decrease in spirometric measurements was seen during exacerbations. There were no statistically significant correlations between changes in the profusion score and changes in FVC or FEV1 for either the whole population or the spirometric decline subgroup [28]. The authors concluded that radiography was inadequate to reliably detect exacerbations of pulmonary sarcoidosis.

Taken together, these results highlight the weaknesses of chest radiography for the monitoring of sarcoidosis. However, a further advantage of serial chest radiographs over PFTs is the detection of pulmonary complications, including aspergilloma. From this point of view, it is the combination of the two tests that is, in essence, helpful in clinical practice.

\section{Chest radiography as a guide for treatment decisions}

Treatment for pulmonary sarcoidosis is usually dictated by the severity of symptoms and/or functional impairment, but chest radiography per se may also guide therapeutic intervention [29-31]. A prospective randomised study conducted by the British Thoracic Society provides some support for long-term corticosteroid therapy in asymptomatic patients with persistent pulmonary infiltrates for at least 6 months [29]. After adjustment for possible confounding factors, the average difference in vital capacity between treated and untreated groups at final assessment was $9 \%$ of the predicted value. In another placebocontrolled study, patients with newly detected stage I or II-III disease and (sub)normal lung function were immediately treated with oral prednisolone for 3 months, followed by inhaled budesonide for 15 months [30]. Treated patients with initial stage II-III, but not stage I, disease improved significantly more in FVC and DL,CO compared with patients on placebo. Functional benefits were maintained after 5 years, but differences were small [31]. It remains uncertain whether modest improvement in asymptomatic stage II-III patients is clinically pertinent and justifies the morbidity associated with treatment.

\section{CHEST COMPUTED TOMOGRAPHY}

\section{Standard CT scanning protocols}

Multidetector CT, combining helical volumetric acquisitions and thin slice thickness $(0.6-1.25 \mathrm{~mm})$, is now accepted as the imaging reference for the initial work-up of patients with diffuse lung diseases (DLDs) [32]. It allows multiplanar reconstructions and post-processing techniques, which are likely to become increasingly useful. Maximum intensity projections enhance the detection and analysis of the distribution of micronodular structures. Minimum intensity projections improve the detection of areas of increased and reduced density and bronchial stenosis [33]. However, multidetector CT acquisitions increase the radiation burden, which should stay "As Low As Reasonably Achievable" [34]. Therefore, in our group, high-resolution CT (HRCT) protocols with acquisition of $1-1.5 \mathrm{~mm}$ thin slices at 10-mm spaced intervals are still preferred in the follow-up of young patients. Additional sections at end expiration can be useful in the presence of airflow obstruction to identify air trapping in patients with small-airway involvement. Administration of contrast agents can be useful to better discern lymphadenopathy and in patients with vascular complications, including pulmonary hypertension $[35,36]$.

\section{Indications for chest CT}

According to the American Thoracic Society/European Respiratory Society/ World Association of Sarcoidosis and Other Granulomatous Disorders expert consensus statement on sarcoidosis [1], CT is warranted in the following circumstances: 1) atypical clinical and/or radiographic findings; 2) normal chest radiography but a clinical suspicion of sarcoidosis; and 3) detection of pulmonary complications. In addition, CT may improve the diagnostic yield of bronchoscopy for obtaining a positive endobronchial [37] or transbronchial biopsy [38] and it is required before endobronchial ultrasound-guided transbronchial needle aspiration (EBUS-TBNA) [39]. CT findings may discriminate between active inflammation and irreversible fibrosis [40-44], with occasional influence on therapeutic decisions. Furthermore, correlations between disease severity on CT and functional impairment have been examined in numerous studies $[23,35,40,44-54]$.

We will first describe pulmonary sarcoidosis as seen on CT and then try to delineate the real contribution of CT in these different situations.

\section{Chest CT features}

CT appearances of sarcoidosis mirror the perilymphatic spreading of granulomatous process observed pathologically. The hallmark of disease is bilateral hilar lymph node enlargement with micronodular pattern [5,55] (fig. 1). However, the spectrum

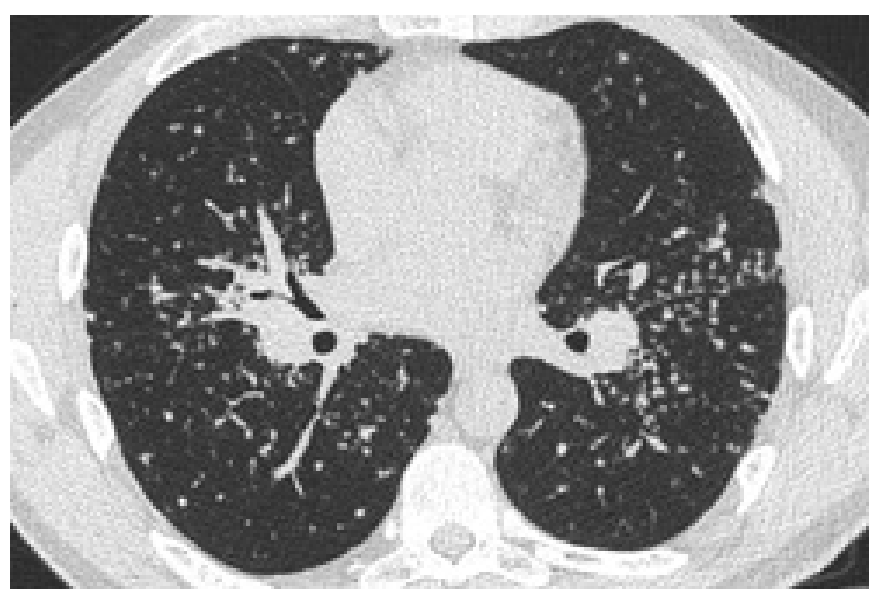

FIGURE 1. Computed tomographic image of pulmonary sarcoidosis with bilateral hilar lymphadenopathy and micronodules with a perilymphatic distribution including spreading along the fissures. 
of disease on CT is extraordinarily protean $[5,55]$ and multiple features or patterns more or less characteristic of the disease may be variously associated in individual patients. Readers can refer to the Fleischner Society glossary for the definition of terms used in this section [56].

\section{Thoracic lymphadenopathy}

Although not necessary in typical stage I disease, CT is more sensitive to detect enlarged lymph nodes than a chest radiograph [57]. Overall, hilar or mediastinal lymphadenopathy are encountered on CT in $47-94 \%$ of patients with sarcoidosis, irrespective of radiographic staging [35, 42, 57-60]. Lymph nodes are usually bilateral but with right-sided predominance [57-60]. In two studies based on the American Thoracic Society lymph node map, the most commonly involved nodal stations, in decreasing order of frequency, were: $4 \mathrm{R}$ (right lower paratracheal); 10R (right hilar); 7 (sub-carinal); 5 (sub-aortic, i.e. aorto-pulmonic window); $11 \mathrm{R}$ (right interlobar); and $11 \mathrm{~L}$ (left interlobar) [59,60]. A median of three lymph nodes were enlarged, as defined by a maximum short-axis diameter $\geqslant 10 \mathrm{~mm}$, and diameter was $\geqslant 20 \mathrm{~mm}$ in $29.1 \%$ of cases [59]. Lymphadenopathy is also common in collagen vascular disease (present in $70 \%$ of cases), idiopathic pulmonary fibrosis (IPF) $(67 \%)$, extrinsic allergic alveolitis (53\%) and organising pneumonia (36\%) [59]. However, the number of enlarged lymph nodes is higher in sarcoidosis and a size greater than $20 \mathrm{~mm}$ in short-axis diameter increases the chance of sarcoidosis [59].

Sarcoidosis lymph nodes are usually non-necrotic and noncompressive, with nodal calcification frequent in longstanding disease. Calcification is present at presentation in $20 \%$ of cases, increasing to $44 \% 4$ years later [42], with egg-shell aspect present in $9 \%$ [58]. The mean diameter of calcified nodes is significantly larger in sarcoidosis, calcium deposition is more commonly focal in sarcoidosis and diffuse in tuberculosis and, when present, hilar nodal calcification is much more likely to be bilateral in sarcoidosis than in tuberculosis (65\% versus $8 \%$ ) [58].

Lymphadenopathy may be unilateral or localised in an unusual site. Although possible in sarcoidosis, the enlargement of internal mammary and pericardial lymph nodes requires exclusion of lymphoma. Enlarged lymph nodes, essentially when calcified, and/or mediastinal fibrosis can rarely provoke extrinsic compression on adjacent organs, including bronchi [61], large pulmonary arteries [36] or veins $[62,63]$, the superior vena cava [64], the oesophagus [65], the left recurrent nerve [66] or the thoracic duct [67].

\section{Pulmonary patterns}

Micronodular opacities with a perilymphatic distribution

Nodules represent aggregates of granulomas [68]. They are seen in $80-100 \%$ of all patients $[40-42,44,45,53,54,69,70]$ but are less frequent in stage IV disease [35]. Most are small, measuring between $1-10 \mathrm{~mm}$ in diameter, and have irregular poorly circumscribed margins. Maximum intensity projection may be helpful to detect micronodules and specify their topographic distribution [33]. They usually show a predilection for the mid/ upper and posterior parts of the lungs with a perilymphatic distribution (fig. 1). They tend to be more abundant around bronchovascular structures and sub-pleurally, along the concavity of chest wall, the mediastinum and/or the fissures, and along the bronchovascular sheath and the interlobular septa
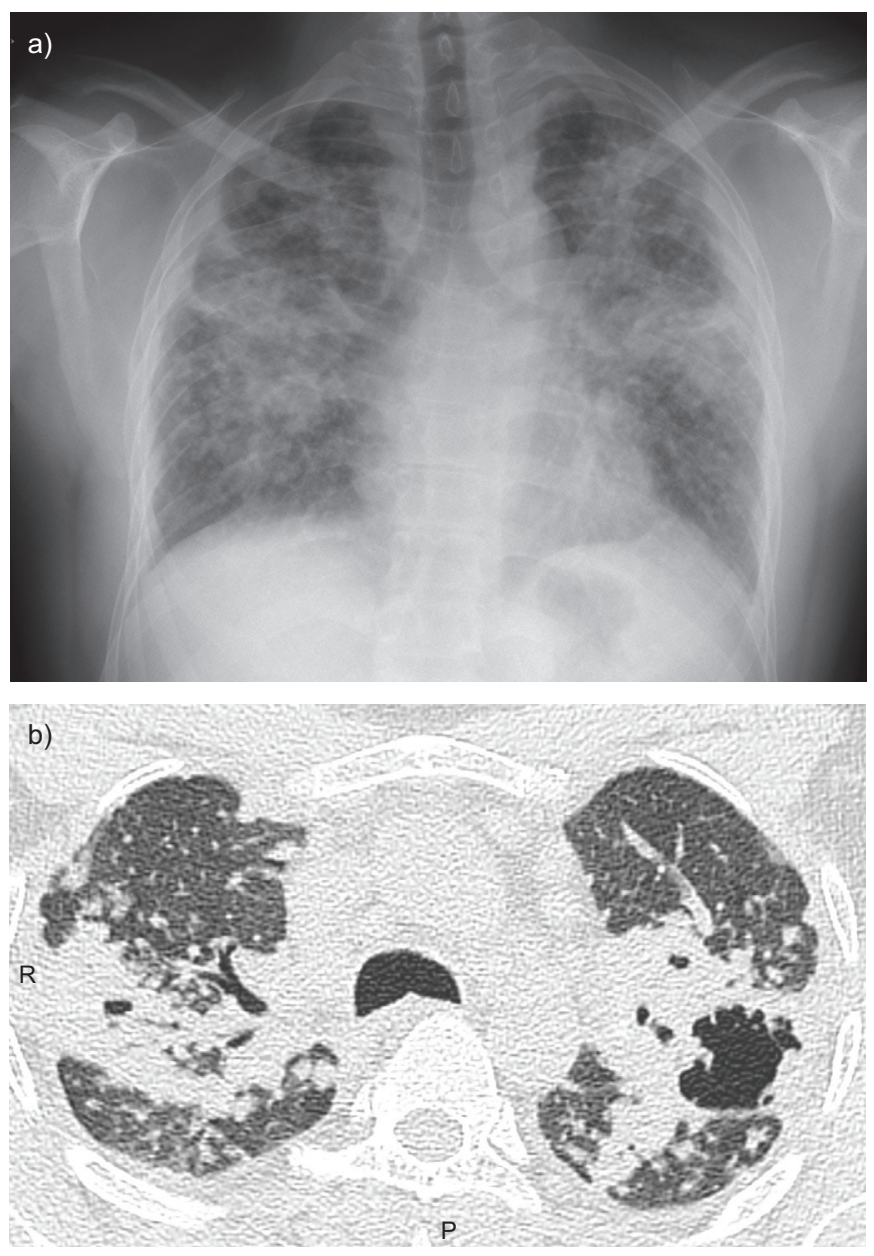

FIGURE 2. a) Chest radiograph and b) computed tomographic image of "alveolar" sarcoidosis associated with profuse micronodular involvement and cavitary lesions on the left.

$[5,55]$. Nodularity can result in a fissural or bronchovascular "beaded" aspect, which is widely accepted as virtually pathognomonic of sarcoidosis (although this has never been formally validated). Irregularity or thickening of the bronchovascular bundles is as a second cardinal sign [4,55]. Peribronchovascular thickening often emanates from the hilar regions in an axial fashion and occasionally gives rise to luminal stenosis [61]. Other diseases distributed along the lymphatics, such as lymphangitic carcinomatosis and lymphoma, are usually readily distinguished from sarcoidosis on CT [71].

Micronodules may be sparse in distribution rather than widespread or asymmetric. They may be dispersed throughout the lungs without any topographic predilection or may exceptionally adopt a haematogenous or a centrilobular configuration rather than perilymphatic, simulating miliary tuberculosis or metastases and hypersensitivity pneumonitis, respectively [72].

\section{Nodular and alveolar opacities}

Small nodules can coalesce into larger ones or masses, which can very rarely cavitate [73-75]. Alveolar or pseudoalveolar consolidations are seen in $12-38 \%$ of patients [35, 41, 44, 45, 54, 76]. However, a predominance of multiple large nodules/masses 

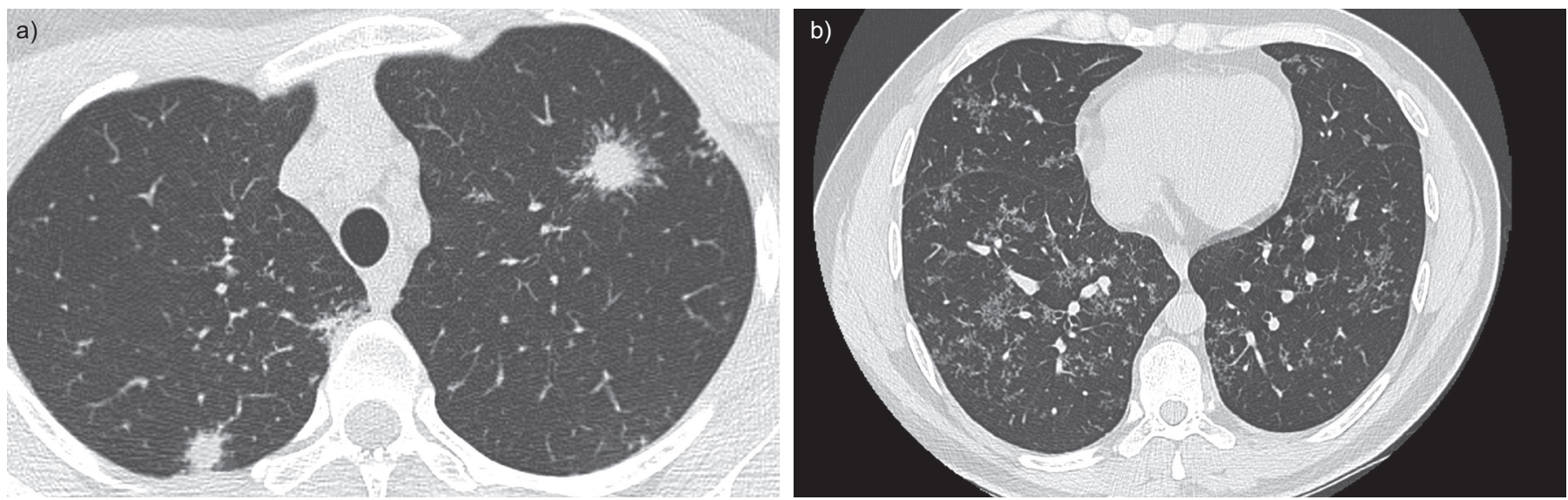

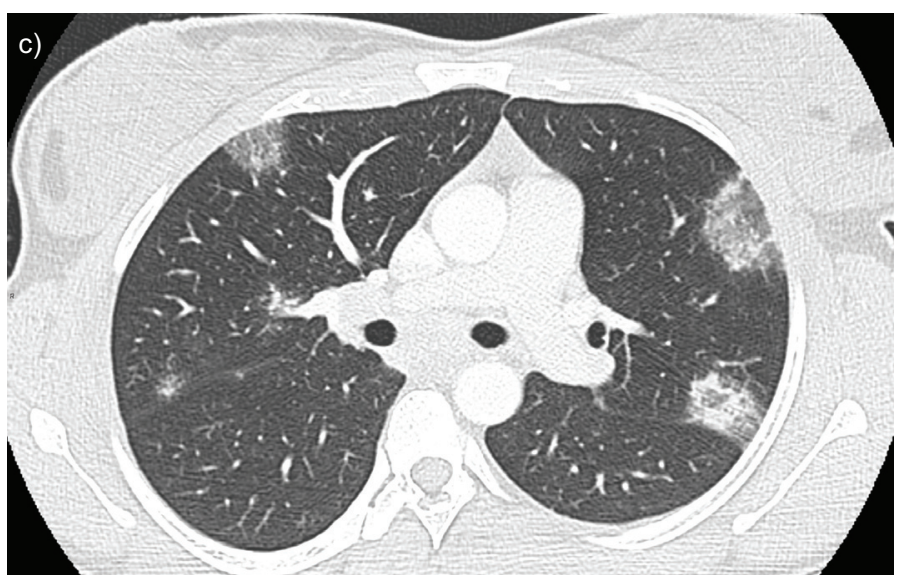

and multifocal consolidations is uncommon in sarcoidosis and can mimic organising pneumonia or malignancy. According to a recent series by MALAISAMY et al. [74], the presentation of such a form of disease is usually acute and symptomatic with an excellent prognosis and it may particularly affect smokers [74]. Nodules/masses and consolidations are homogeneous or inhomogeneous, measure $10-80 \mathrm{~mm}$ in diameter, and are usually located in the mid/upper lobes, along the bronchovascular bundles or sub-pleurally, sometimes with the presence of a central air bronchogram [74, 77]. They are characterised by illdefined contours as they fade to a micronodular pattern toward the surrounding lung (fig. 2). In addition to these lesions, other more representative abnormalities such as lymph nodes are usually associated $[74,77]$. Solitary mass-like nodule and alveolar consolidation are exceedingly rare in sarcoidosis [74, 78].

Necrotising sarcoid granulomatosis, which is defined pathologically by a sarcoid-like granulomatous reaction with vasculitis (involving both arteries and veins) and noncaseating necrosis, shares many clinical and radiological features with alveolar sarcoidosis but is traditionally viewed as a separate entity [79].

Cavitary lesions in sarcoidosis are believed to result from either ischaemic necrosis (with extrusion of hyaline material from conglomerate granulomas) or angiitis [73]. Reported rates of cavitary lesions were $3.4 \%$ and $6.8 \%$ in two CT studies, respectively $[40,75]$. According to a recent series by HouRs et al. [73], cavitary lesions manifest as thin-walled cysts in most cases or as cavities with thick wall or developing inside nodules or condensations [73] (fig. 2). Cavitary lesions are variable in
FIGURE 3. Computed tomographic images of a) the "sarcoid galaxy" sign (irregular nodule resulting of the confluence of numerous micronodules), b) the "sarcoid cluster" sign (clusters of micronodules without confluence) and c) the "reversed halo" sign (ring of micronodules surrounding central ground-glass opacity, which is a very rare finding in sarcoidosis).

size and, although occasionally found in isolation, they are more likely to be multiple and bilateral. They usually arise in patients with severe and active sarcoidosis. The evolution of cavitary lesions is variable. A wall thinning is usually observed under treatment whereas a wall thickening is always associated with an infectious complication [73]. Pneumothorax can occur [73, 80]. Because primary cavitary sarcoidosis is rare, granulomatosis with polyangiitis (Wegener's) and superimposed infection should always be excluded.

\section{"Sarcoid galaxy" and "sarcoid cluster" signs}

Two terms have recently been coined in sarcoidosis to describe a particular distribution of nodules: the "sarcoid galaxy" sign (fig. 3a) and the "sarcoid cluster" (fig. 3b) sign [81]. The "sarcoid galaxy" is a large nodule, usually with irregular boundaries, encircled by a rim of numerous tiny satellite nodules. It is usually multiple throughout the lungs. Pathologically, the "sarcoid galaxy" represents innumerable coalescent granulomas that are much more concentrated in the centre of the lesion than at the periphery [75]. The "sarcoid cluster" also corresponds to rounded or long clusters of many small nodules that are close to each other but, in contrast to those of the "sarcoid galaxy", not confluent. Pathologically, the "sarcoid cluster" represents granulomas without coalescence [82]. Although initially reported as a specific manifestation of sarcoidosis, these two signs have subsequently also been identified in other granulomatous diseases, including tuberculosis, silicosis and cryptococosis. Certain associated features help to differentiate these diseases [81]. 


\section{Linear opacities}

Nodules are the only CT abnormality in approximately onethird of patients, but are more commonly associated with other lesions. Thickened or nodular interlobular septae (septal lines) are frequent, with a wide reported prevalence range (26-89\%) $[35,41,42,44,45,53,76]$, and are usually less prominent than nodules. Non-septal lines are more rare. Fibrotic septal lines are often irregular and/or distorted. Linear opacities are sometimes organised as a polygonal configuration in a reticular network, with or without ground-glass opacity [35, 40,53], which can divulge the presence of pulmonary hypertension [35, 36]. Lymphangitic carcinomatosis is usually characterised by more extensive, asymmetric and marked involvement of the interlobular septa and subpleural space than sarcoidosis, with no architectural distortion [71].

\section{Ground-glass opacification}

The frequency of ground-glass opacity varies from 16-83\% $[35,41,42,44,45,53,76]$. The pathological significance of ground-glass opacity is not univocal, as this CT feature can result from the confluence of multiple micronodular granulomas and/ or from fibrotic lesions [68]. Ground-glass opacity seems to be more common at presentation than later in the disease course [40]. Although seldom the predominant abnormality [40, 44, 45, $48,50,52]$, ground-glass opacity is usually multifocal, rather than extensive. Extensive ground-glass opacity tends to have a superior predominance, with ill-defined margins, and it is often overlaid on a background of subtle micronodularity (fig. 4) and associated with lymph nodes [83].

\section{Scarring and fibrosis}

Lung architectural distortion is constant in stage IV disease $[35,40]$, and, overall, is reported in $20-50 \%$ of patients [40, 42, 44, 76]. It includes abnormal displacement of hila, fissures, bronchovascular bundles and distortion of secondary pulmonary lobules. Posterior displacement of the main or upper lobe bronchus and volume loss (particularly in the posterior segment of upper lobes) are characteristic features of fibrotic sarcoidosis [35]. Bronchi may be deformed, angulated, crossed or stenosed [35]. Conglomerate masses often surround and encompass the bronchi and vessels. They are a frequent feature in stage IV disease $(60 \%)$ and are usually central and associated with bronchial distortion [35] (fig. 5).

In advanced fibrotic sarcoidosis, traction bronchiectasis, honeycombing, other types of cystic destruction, bullae and paracicatricial emphysema are encountered, mainly in mid/upper areas. Three distinct patterns of distribution have been recognised in stage IV disease [35]: the bronchial distortion pattern (47\% of patients), with or without co-existent masses; the honeycombing pattern (29\%); and the linear pattern $(24 \%)$. These patterns are associated with different functional profiles (see below) [35]. In a serial CT study, ground-glass opacities and consolidations seen on the initial CT scan tended to evolve into honeycombing whereas conglomeration masses shrank and evolved into bronchial distortion [45].

When present in sarcoidosis, honeycombing usually affects the upper and perihilar regions [35] (fig. 6a), which is very dissimilar from IPF. Interestingly, a pattern of IPF-like honeycombing has been exceptionally reported in sarcoidosis, showing a striking prominence in the lower lung zones with a peripheral and
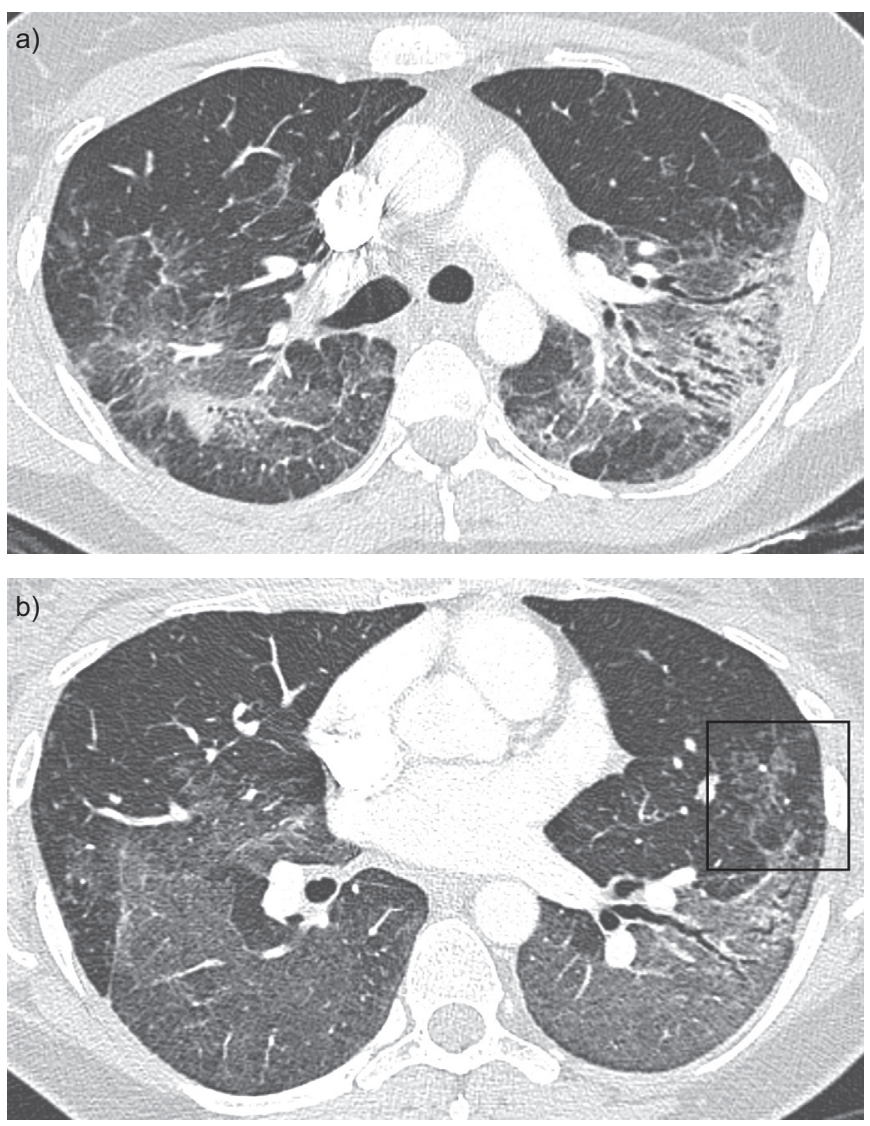

FIGURE 4. Computed tomographic images of a 35-yr-old female with pulmonary sarcoidosis and extensive ground-glass opacification. The diagnosis of sarcoidosis is suspected given the association with more characteristic signs of sarcoidosis, including a) bronchial distortion in the superior and posterior regions and b) the presence of few micronodules with a perilymphatic distribution (boxed area)

subpleural distribution, or a diffuse distribution [35, 84]. Pathological examination is available for a handful of patients. A particular localisation of granulomas has been mentioned along the alveolar septa [84, 85], together with a so-called "chronic interstitial pneumonia" sometimes taking the appearance of usual interstitial pneumonia [84-87].

\section{Airway involvement}

In sarcoidosis, central and distal airway involvement may result from different mechanisms and lead to airflow limitation [23, 50, 61]. Bronchial involvement, as judged by regular or irregular mural thickening and luminal narrowing, is detected on CT in $65 \%$ of patients and is usually concordant with endoscopic findings and endobronchial mucosal granulomas [37]. CT can also demonstrate extrinsic or intrinsic stenosis (see later in this review), traction bronchectasis and bronchial distortion (fig. 5). Minimum projection can provide an additional assessment of these lesions since it is an accurate tool to study proximal airways [33]. Increasing attention has been devoted to airtrapping [23, 47, 50, 52, 54, 88-91]. Mosaic decreased attenuation caused by air-trapping is often obvious on inspiratory images and is enhanced on expiration. It has been cited as an extremely common feature, being identified on expiratory scans in 83.3-98\% 

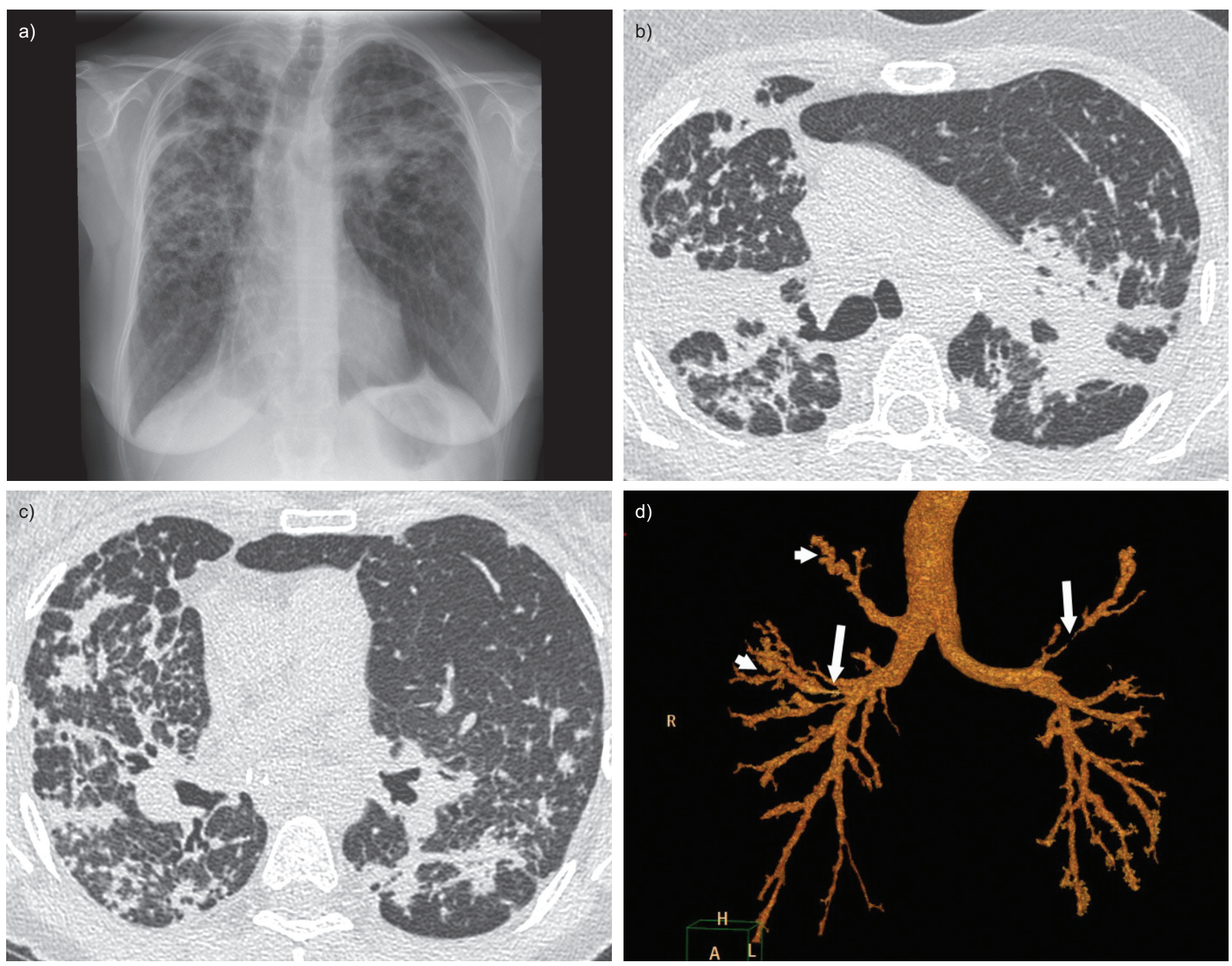

FIGURE 5. a) Chest radiograph and b, c) computed tomographic images of a 50-yr-old female with obstructive pattern (forced expiratory volume in $1 \mathrm{~s} /$ forced vital capacity ratio 68\%) showing conglomerated masses in the upper lobes with posterior and superior displacement of the main bronchus and distorted airways (angulation, dilatation). Notably, scar emphysema is observed in the anterior part of the lung with reticulations on the left. The numerous nodules and micronodules suggest probable reversibility of lesions. d) Volume rendering technique image of the bronchi improves the detection of multiple bronchial stenoses (long arrows) and traction bronchiectasis (short arrows).

of patients $[47,50,52,54,91]$ and may constitute the sole CT evidence of pulmonary sarcoidosis $[52,90]$. This frequency is probably overestimated by these studies, where the definition of air-trapping was ambiguous. There is no difference between the predominant inspiratory CT patterns [52] or smoking status [54] with regard to the prevalence or extent of air-trapping. It has been suggested that air-trapping reflects small-airway involvement by peribronchiolar or intraluminal granulomas or fibrosis.

Pleural involvement

Pleural effusions may result from pleural granulomatous involvement or from the blockage of interlobular septal lymphatic channels by granulomas. Apparent pleural thickening often represents inward retraction of extrathoracic soft tissue and extrapleural fat, rather than a true pleural abnormality. Pleural involvement is rare in sarcoidosis, with pleural effusions observed in less than $5 \%$ of patients on chest radiography $[7,8]$ and in $2.8 \%$ on ultrasonography [92]. In CT studies, pleural surface thickening is evidenced in $11-33 \%$ of patients $[40,42,70]$ and a mild effusion in $8.2 \%$ [93]. Pneumothorax is exceptionally seen in advanced bullous sarcoidosis or as a consequence of the rupture of a cavitary lesion $[73,80]$.

\section{Other signs}

A "halo" sign [94, 95], a "fairy ring" sign [96], and a "reversed halo" sign [81] (fig. 3c) have been rarely reported in sarcoidosis. The "halo" sign indicates ground-glass opacity surrounding a pulmonary nodule, which can result from a large variety of causes, such as infection, mainly invasive aspergillosis in immunocompromised patients, neoplastic and inflammatory disorders [97]. In one case with sarcoidosis, the "halo" sign represented intra-alveolar granulomas and aggregates of macrophages in the alveolar spaces with thickened alveolar septa at pathology [94]. The reverse halo sign refers to a focal, rounded ground-glass area 

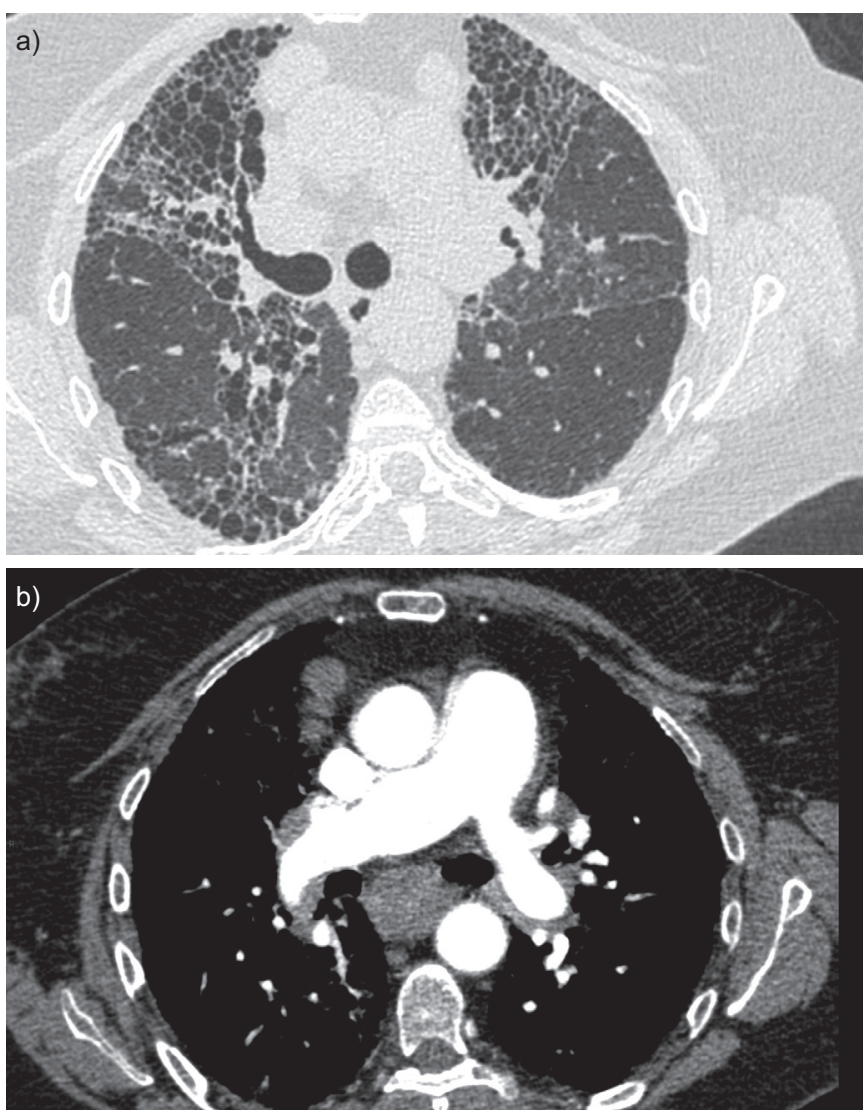

FIGURE 6. Computed tomographic (CT) images of a 67-yr-old female with fibrosing pulmonary sarcoidosis with honeycombing pattern and pulmonary hypertension. a) Honeycombing predominates in the upper and perihilar regions, and along the bronchovascular bundles. Note the various sizes of the cysts. b) Contrast-enhanced CT shows the widest diameter of the main pulmonary artery with a diameter superior to that of the ascending aorta and slight vascular compression by enlarged mediastinal lymph nodes.

bordered by a nearly complete ring of consolidation [81]. Although long regarded as highly specific of organising pneumonia, this sign has further been cited in various infectious and noninfectious conditions, including sarcoidosis [81]. According to a recent series, the presence of nodular walls or nodules inside the halo of the reversed halo sign is very suggestive of granulomatous diseases [81]. The term fairy ring sign has been used in a unique patient with sarcoidosis [96]. It was formed by a halo with nodular border, but by contrast with the reversed halo, the central area of the lesion was composed of normally aerated lung tissue. The authors suggested that the ring of granulomatous tissue extended concentrically from a specific point in the lung [96].

\section{Role of chest CT in the diagnosis of sarcoidosis}

Diagnostic accuracy of CT versus clinical diagnosis and chest radiography

The accuracy of HRCT for the diagnosis of DLDs depends on the underlying disease. GRENIER et al. [98] evaluated supplementary information yielded by HRCT after taking into account clinical data and radiographic findings [98]. Computer-aided diagnoses were made by applying a Bayesian model in a large population of DLDs, including patients with pulmonary sarcoidosis. For sarcoidosis, the percentages of correct diagnosis with a high level of confidence were $33-42 \%$ with clinical data alone, 52$76 \%$ with clinical and radiographic findings and $78-80 \%$ when HRCT findings were integrated [98]. This relatively small difference emphasises the opinion that CT adds little information when a confident diagnosis of sarcoidosis can be made from typical clinical and radiographic presentation [99]. However, it understates the true compelling diagnostic role of CT in other less straightforward cases.

\section{Diagnostic contribution of CT}

In the appropriate clinical setting, the observation of the characteristic picture of sarcoidosis on CT (bilateral hilar lymph node enlargement with perilymphatic micronodular pattern) points to a highly confident (virtually pathognomonic) diagnosis (table 2 and fig. 1). CT can reveal these abnormalities lying below the resolution limits of chest radiography, which is important when there is a clinical suspicion of sarcoidosis with normal chest radiography. $\mathrm{CT}$, in concert with several other standard diagnostic tools, increases the diagnostic likelihood of sarcoidosis, in particular when the disease is confined to one extrapulmonary organ and the biopsy is considered too risky (as in central nervous system involvement). It seems especially useful in the evaluation of elderly females with uveitis [100, 101].

In atypical clinical and/or radiographic variants of sarcoidosis, there is a broad variety of differential diagnoses. In radiological practice, the diagnosis of interstitial lung diseases is usually based on the identification of a predominant pattern on CT. In sarcoidosis, the combination of features is at least as decisive. Bilateral hilar lymphadenopathy, when large, and/or perilymphatic micronodular pattern are probably the most important findings, whether predominant or not. These signs, which can be subtle and must be looked for carefully by the radiologist, are highly prevalent except in advanced pulmonary fibrosis. They are present even in rather uncommon patterns, in particular in alveolar or ground-glass patterns (fig. 4), this association improving the level of diagnostic confidence considerably (table 2). Proximal bronchial distortion is also an important finding in fibrotic cases. Using a logical analysis of data technique, MARTIN et al. [83] recently demonstrated the value of combining CT features for the diagnosis of sarcoidosis with predominant ground-glass opacification.

\section{CT as an aid to obtaining biopsy/cytology material}

There is a clear association between bronchial abnormalities seen on CT and the presence of mucosal granulomas on endobronchial biopsy [37]. Similarly, DE BOER et al. [38] recently demonstrated that the total extent of parenchymal disease on $\mathrm{CT}$ in addition to the pattern and lobar distribution, i.e. reticular pattern and ground-glass opacification, predicted the likelihood of a positive transbronchial biopsy at bronchoscopy. CT may help to guide EBUS-TBNA [39]. Lastly, CT-guided transthoracic needle biopsy of mediastinal lymph nodes [102] or lung nodules [74] is occasionally very helpful in establishing the diagnosis.

\section{Role of chest CT in the prognosis of sarcoidosis}

Correlations between chest CT and disease activity

Correlations between CT findings and classic markers of sarcoidosis activity, including serum angiotensin-converting 
TABLE 2 Diagnostic confidence for sarcoidosis according to the predominant pattern and relevant associated features on computed tomography

\begin{tabular}{|c|c|c|}
\hline Predominant pattern & Associated features & Diagnostic confid \\
\hline \multirow[t]{2}{*}{ Large bilateral hilar lymphadenopathy } & Isolated & High" \\
\hline & Perilymphatic micronodules & Very high \\
\hline \multirow[t]{2}{*}{ Unilateral lymphadenopathy } & Isolated & Very low \\
\hline & Perilymphatic micronodules & Intermediate $^{+}$ \\
\hline \multirow[t]{2}{*}{ Mediastinal, internal mammary or pericardial lymphadenopathy } & Isolated & Very low \\
\hline & Perilymphatic micronodules & Low \\
\hline \multirow[t]{2}{*}{ Perilymphatic micronodules } & Cluster sign & High \\
\hline & Large bilateral hilar lymphadenopathy & Very high \\
\hline \multirow[t]{4}{*}{ Nodules/masses or condensations } & Unique & Very low \\
\hline & Perilymphatic micronodules & High \\
\hline & Sarcoid galaxy & High \\
\hline & Large bilateral hilar lymphadenopathy & High \\
\hline \multirow[t]{4}{*}{ Cavitations $^{\#}$} & Isolated & Very low \\
\hline & Perilymphatic micronodules & Intermediate $^{+}$ \\
\hline & Sarcoid galaxy & Intermediate $^{+}$ \\
\hline & Large bilateral hilar lymphadenopathy & Intermediate $^{+}$ \\
\hline \multirow[t]{3}{*}{ Ground-glass opacification } & Isolated & Low \\
\hline & Perilymphatic micronodules & High \\
\hline & Large bilateral hilar lymphadenopathy & High \\
\hline \multirow[t]{3}{*}{ Pulmonary fibrosis } & Basal and peripheral honeycombing & Very low \\
\hline & Upper/mid and central honeycombing & Intermediate \\
\hline & Bronchial distortion & $\mathrm{High}^{\S}$ \\
\hline
\end{tabular}

\#: cavitations usually develop inside nodules/masses or condensations; ": in asymptomatic patients with an unremarkable physical examination or acute symptoms (i.e. uveitis, polyarthritis or erythema nodosum); ${ }^{+}$: need to exclude superimposed comorbidities, including infections, before attributing the pattern to sarcoidosis; ${ }^{\text {s: }}$ : when bronchial distortion has an upper predominance, with deformed, angulated, crossed or stenosed proximal bronchi and posterior displacement of the main or upper lobe bronchus.

enzyme (SACE) levels, bronchoalveolar lavage (BAL) lymphocytosis, and gallium scan signal, are inconclusive or discrepant [40, 41, 43, 44,46]. Much more has been learned from studies of the reversibility of CT features (spontaneously or under treatment) on serial examinations (table 3) [42, 44, 45, 76]. Architectural distortion, traction bronchiectasis, honeycombing and bullae are consistently irreversible. Micronodules, nodules, peribronchovascular thickening and consolidation are wholly or partially reversible in most, but not all, cases. The evolution of ground-glass and linear opacities is more variable. Ground-glass opacity may steady, worsen or improve over time, reflecting the fact that it may represent either granulomas or fine fibrosis
$[68,103]$. A coarse texture or concomitant traction bronchiectasis increases the likelihood of underlying fibrosis [103]. Similarly, septal thickening from intense granulomatous infiltration tends to reverse, whereas irregular distorted lines are more likely to be fibrotic.

Thus, discrimination between active inflammation and irreversible fibrosis with CT may occasionally be helpful when the decision to initiate or continue potentially toxic treatment is marginal. For instance, in stage IV disease a trial of therapy might be warranted if a potentially reversible component is still visible on $\mathrm{CT}$ [35]. This role of CT may be supplanted by PET-CT in the future.

TABLE 3 Reversibility of sarcoidosis features observed on computed tomography (spontaneously or under therapy)

\begin{tabular}{|c|c|c|}
\hline Micronodules & Architectural distortion & Consolidation ${ }^{\#}$ \\
\hline \multirow[t]{2}{*}{ Peribronchovascular thickening } & Honeycombing & Linear opacities $^{+}$ \\
\hline & Bullae & \\
\hline
\end{tabular}




\section{Correlations between chest CT and baseline lung function}

Many studies have explored the relationships between CT findings and PFTs [22, 23, 35, 40, 44-48, 50-54] with variable results, probably reflecting the diversity of imaging analysis and scoring. In the study of REMY-JARDIN et al. [44], lungs were divided into three zones and a percentage involvement score was assigned for abnormal parenchymal patterns (nodules, consolidation, lung distortion, septal and nonseptal linear, ground-glass opacity and honeycombing). The overall extent of disease was the summation of the scores for each type of abnormality. Profusion of septal lines was the only CT finding that correlated with initial disease activity (as assessed by SACE levels and BAL lymphocytosis). Significant but low correlation was observed between the scores of CT abnormalities and either initial FEV1, FVC or DL,CO, except for nodules. $\mathrm{CT}$ findings could not help predict the further evolution of disease activity and functional changes over time [44]. A more simple semi-quantitative CT scoring system, first described by OBERSTEIN et al. [43], served in the correlation study of DRENT et al. [48]. This consisted of coarse quantification of the extent of abnormal parenchymal patterns (thickening or irregularity of the bronchovascular bundle, nodules, septal and nonseptal lines, and consolidation, including ground-glass opacity) using a fourpoint scale $(0=$ no lesions found; $1=$ up to $33 \% ; 2=$ up to $66 \%$; and $3=$ more than $66 \%$ ), and the extent of focal pleural thickening and lymph node enlargement $(0=$ no pathological findings; $1=$ minor; 2 = moderate; and $3=$ pronounced changes). The total score was obtained by adding the individual subscores. Interobserver agreement was moderate for the subscores (weighted $\kappa$ 0.34-0.65, with worse results for bronchovascular bundle and lymph nodes), but excellent results for the total score (intraclass correlation coefficient 0.99 ). All CT subscores, except lymph nodes enlargement, were correlated with FEV1, FVC, DL,CO, maximal arterial oxygen tension and maximal $\mathrm{P}(\mathrm{A}-\mathrm{a}), \mathrm{O}_{2}$, whereas the chest radiographic stage was not.

In other studies, CT was classified according to subjective appraisal of the predominant pattern of involvement. LOPES et al. [51] investigated the relationship between outcome measures of cardiopulmonary exercise testing (CPET) and predominant CT pattern: nodules, ground-glass opacity, and traction bronchiectasis plus honeycombing. PFTs and CPET results were close to normal only for patients with predominant nodules. Patients with predominant ground-glass opacity showed intermediate values of FEV1, FVC and DL,CO compared with patients of the other two groups. Interestingly, only the CPET results were able to differentiate patients with predominant ground-glass opacity and those with predominant traction bronchiectasis and honeycombing, with a significantly decreased peak oxygen uptake and breathing reserve, and increased $P(A-a), \mathrm{O}_{2}$ for the latter [51]. As discussed previously, ABEHSERA et al. [35] separated three CT patterns of fibrotic pulmonary sarcoidosis, which were associated with different functional profiles. The interobserver agreement for recognising the main CT pattern was very good as observers agreed in $80 \%$ of cases $(\kappa=0.87)$. Bronchial distortion pattern was associated with lower expiratory airflow rates, while honeycombing pattern was associated with restriction and lower $D \mathrm{~L}, \mathrm{CO}$, and functional impairment was relatively minor when linear pattern predominated [35].

In summary, the degree of functional alteration is usually linked to an overall CT score but most correlations are weak $[40,46,48$,

\section{TABLE 4 Underlying mechanisms of airflow limitation observed on computed tomography and probability of response to therapy}

Mechanism

Response to therapy

$\begin{array}{lc}\text { Bronchial distortion } & \text { No } \\ \text { Peribronchovascular thickening } & \text { Yes } \\ \text { Intrinsic bronchial stenosis } & \text { Variable } \\ \begin{array}{l}\text { Extrinsic bronchial compression } \\ \text { by lymphadenopathy }\end{array} & \text { Yes } \\ \text { Air-trapping } & \text { Variable }\end{array}$

\#: these mechanisms are usually admixed; " : when lymph nodes are not calcified

53]. Total CT score seems superior to chest radiographic staging [48] but its real clinical impact is questionable. Correlations between PFTs and the score of specific patterns are hardly interpretable because of considerable overlap among CT categories, but they sometimes give clues to the understanding of
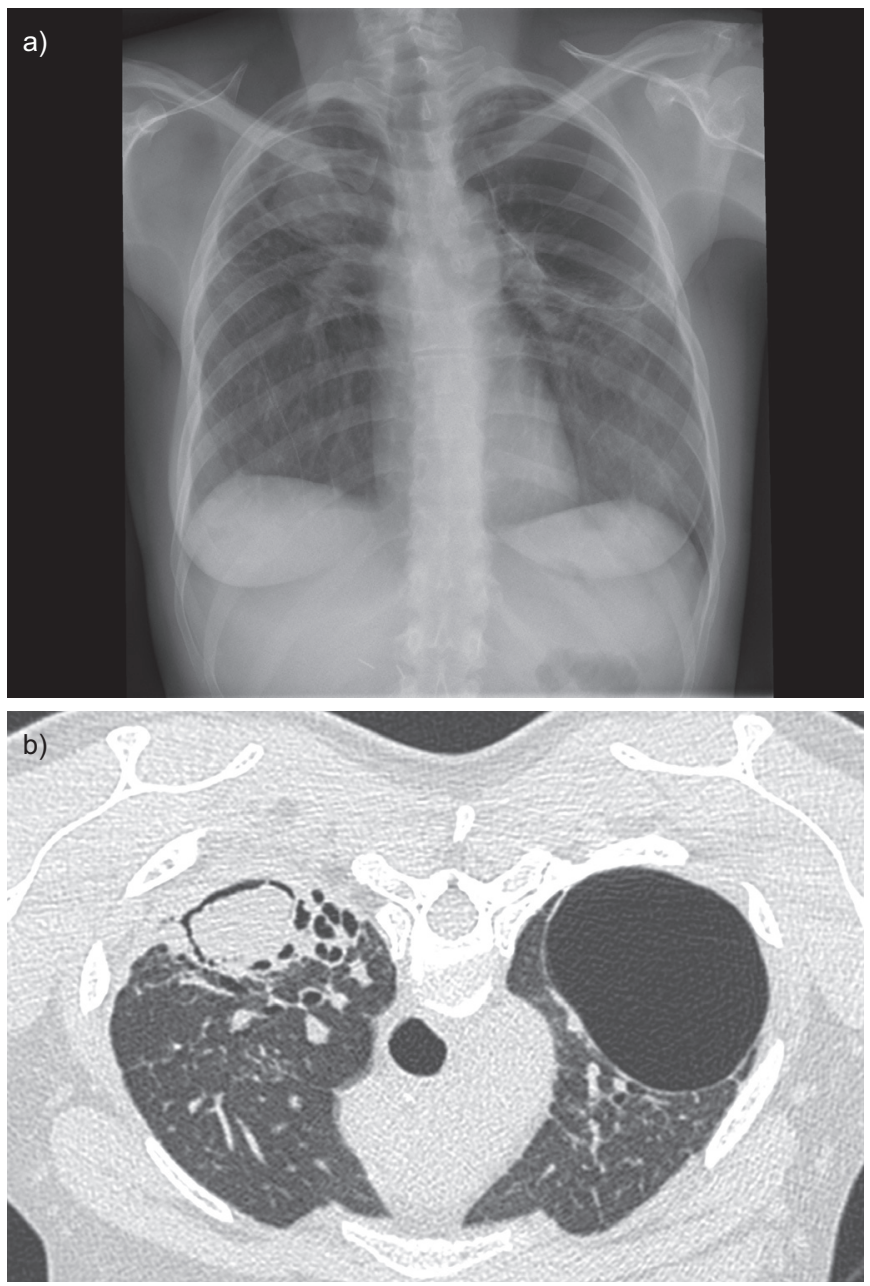

FIGURE 7. a) Chest radiography and b) computed tomographic image (performed in procubitus) in a 43-yr-old female with cystic lung lesions complicated with aspergilloma (fungus ball with a crescent sign in the right lung). 

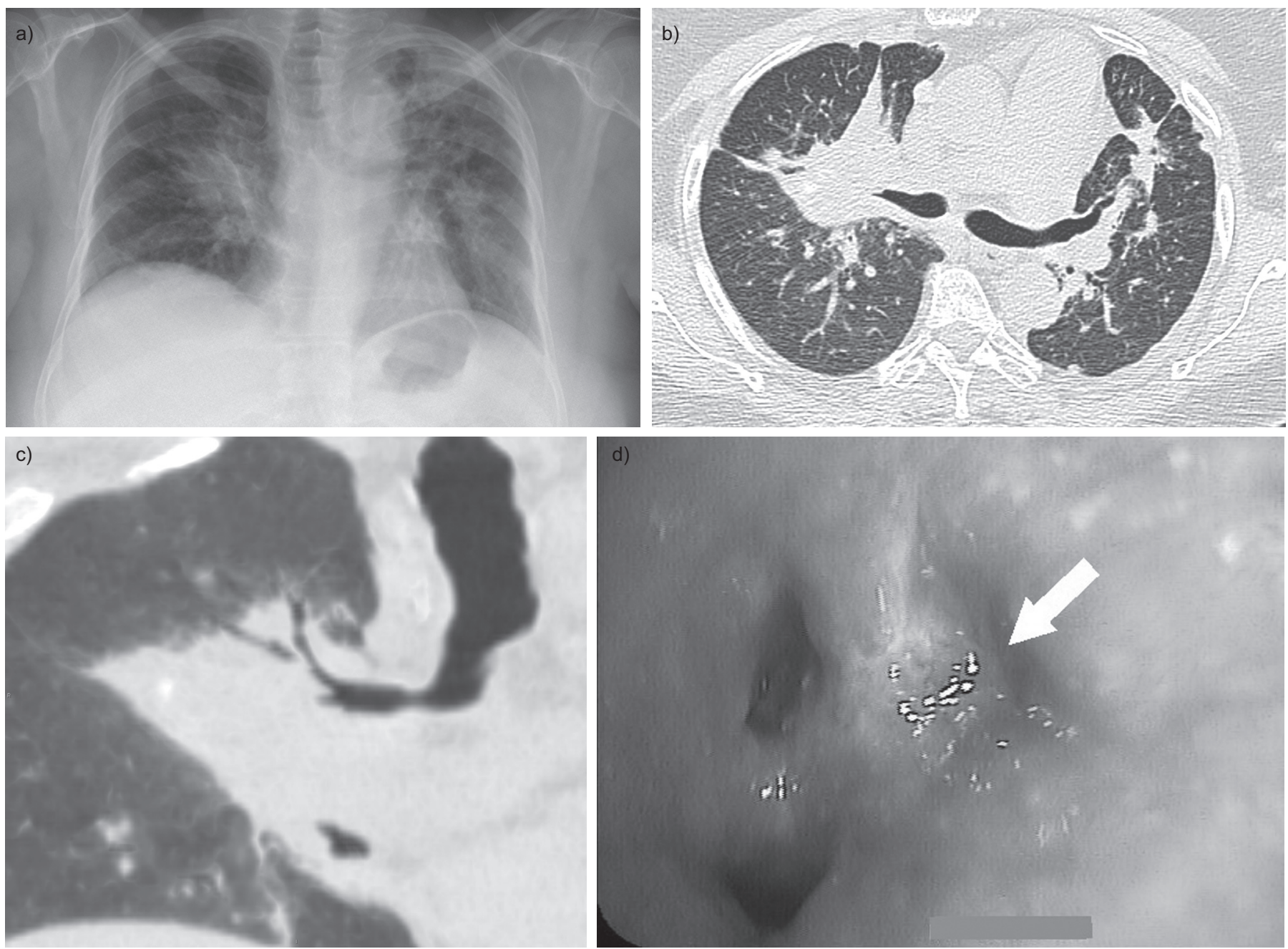

FIGURE 8. a) Chest radiography and b, c) computed tomographic images of a 60-yr-old female with stenoses of the dorsal bronchus of the right upper lobe with atelectasis. Minimum intensity projection reconstruction in the coronal plane improves the detection of bronchial stenoses (c), which are confirmed during bronchoscopy (white arrow, d).

disease complications, in particular airflow limitation $[22,23$, 50]. The reported frequency of airflow limitation is wide in sarcoidosis, with an estimate of $8.8 \%$ of patients in a recent prospective study [22]. It is known to portend a higher risk of mortality [25]. CT is a reliable method to identify the underlying mechanisms of airflow limitation and it enables prediction of the therapeutic response (table 4). In a case-control study, NACCACHE et al. [23] demonstrated that CT patterns of airway involvement (i.e. bronchial distortion, peribronchovascular thickening, air-trapping, and bronchial compression by enlarged lymph nodes) were found more frequently, scored higher, and were more often multiple in patients with airflow obstruction than in those without. Furthermore, functional improvement under treatment was observed more frequently in patients with predominant peribronchovascular thickening in comparison to those with predominant bronchial distortion. Notably, interobserver agreement was good for identifying the CT patterns of airway involvement (agreement for $89 \%$ of cases, $\kappa=0.85$ ) [23]. In the study by HANDA et al. [22], the only CT morphological determinant of lower FEV1/FVC was peribronchovascular thickening. HANSELL et al. [50] demonstrated that the extent of reticular pattern was independently associated with several indices of airflow obstruction, including FEV1, FEV1/FVC, maximal expiratory flow (MEF) at $25 \%$ above residual volume (RV), MEF at $50 \%$ above RV and RV/total lung capacity (TLC). Air-trapping is associated with evidence of small-airway obstruction including maximal expiratory flow between of FVC, $\mathrm{RV}$ and/or RV/TLC in some studies [47, 52, 90], whereas in others it only contributes little to airflow obstruction [50, 54].

\section{Role of chest CT in the monitoring of sarcoidosis}

Once the diagnosis of sarcoidosis is secure, CT makes only a small contribution to monitoring in most subjects. The cost and the radiation hazard of repeated and superfluous exams in young patients have to be kept in mind. Moreover, although no study has clearly outlined the additional information provided by serial CTs compared with PFTs and chest radiography, it is probable that $\mathrm{CT}$ is too sensitive, revealing changes that are not necessarily relevant in the practical care of patients. Instead, clinical experience amply supports its role in the detection 
of pulmonary complications, in particular when a patient presents with unexplained worsening of respiratory symptoms, haemoptysis, disproportionately impaired lung function or airflow obstruction, uncertain chest radiographic abnormalities, aspergilloma or pulmonary hypertension.

\section{Aspergilloma}

Mycetoma formation has been reported in about $2 \%$ of sarcoidosis patients, essentially those with advanced fibrocystic or cavitary disease [104]. Aspergilloma is more readily visualised using chest $\mathrm{CT}$ than radiography, which generally reveals a cavity containing a solid mass, with or without a characteristic air crescent. The fungus ball can be mobile within the cavity when the patient is turned from the supine to the prone position (fig. 7). In the presence of a cavitary lesion, the thickening of the wall and adjacent pleura points to aspergilloma and is sometimes the earliest sign before any changes are visible inside the cavity [73]. Aspergilloma may be multiple and bilateral [104], and this is best appreciated by CT and imperative to recognise before surgery.

\section{Pulmonary hypertension}

The prevalence of pre-capillary pulmonary hypertension does not traditionally exceed $5 \%$ of all sarcoidosis patients but it largely depends on the stage of disease. Although usually attributed to the destruction of distal capillary bed by fibrotic process and/or to the resultant chronic hypoxaemia, various alternative mechanisms come into play, including extrinsic compression of large pulmonary arteries by enlarged lymph nodes or mediastinal fibrosis [4], specific granulomatous or fibrotic vascular involvement that sometimes simulates pulmonary veno-occlusive disease [36, 105], and vasoconstriction by vasoactive factors. Contrast-enhanced CT may raise the possibility of pulmonary hypertension when the widest diameter of the main pulmonary artery is larger than $30 \mathrm{~mm}$ or superior to that of the ascending aorta (fig. 6b) but this sign is poorly reliable [106]. Contrast-enhanced CT can also help to recognise underlying mechanisms by showing vascular compression or both extensive septal reticulations and ground glass opacity in case of pulmonary veno-occlusive disease [36]. Most importantly, contrast-enhanced CT rules out pulmonary embolism, which has been recently associated with sarcoidosis [107].

\section{Bronchial stenosis}

Significant bronchial stenosis is very rare and may occur at any stage of the disease [108]. Obstruction may be the consequence of endobronchial granulomatous involvement and extrinsic compression by enlarged lymph nodes [61]. The stenoses can be solitary or multiple, lobar or segmental and may cause or contribute to pulmonary symptoms [61, 108]. The left upper lobe $(44.5 \%)$, the right upper and middle lobes (15.5\% each), and the left lower lobe (11\%) are most often affected. Apart from depicting atelectasis and nodal external reduction of bronchial lumen, CT is useful in determining the extent and nature of bronchial stenosis (fig. 8) [37, 108]. However, it cannot replace bronchoscopy, as it leads to false-positive results, incorrectly predicting the presence of focal bronchial abnormalities in up to $14 \%$ of patients $[37,109]$. New techniques of reconstruction of the bronchial tree may improve the assessment of airway involvement.

\section{OTHER IMAGING TECHNIQUES}

Despite inherent pitfalls, due mainly to the composition of lung tissue and physiological motion (cardiac pulsation and respiration), magnetic resonance imaging (MRI) is gaining attention in pulmonary imaging [110]. However, data are lacking and relatively old in sarcoidosis [111-115] using unenhanced T1 and T2-weighted MRI. GAETA et al. [116] first used gadolinium enhanced thoracic MRI in a cohort of DLDs, including 10 patients with sarcoidosis, and showed enhancement of pulmonary lesions in five out of seven patients with active disease [116]. More recent development in diffusion or perfusion imaging could be of major interest to evaluate regional disease activity [117].

\section{CONCLUSION}

Imaging makes a major contribution to the diagnosis and management of sarcoidosis patients. Despite substantial disagreement about the recognition of radiographic stages, Scadding classification still provides a rough but invaluable evaluation of disease outcome. The comparison of serial chest radiography with pulmonary function for the detection of change in disease severity and for the assessment of treatment response requires further studies. Although not necessary in all patients, chest CT is of outstanding utility for the diagnosis of sarcoidosis and its complications in selected cases. CT scores are better correlated with disease activity and functional impairment than radiography, but the real clinical relevance of such correlations is uncertain. A better definition of end-points is crucial in sarcoidosis, in particular for the quality of clinical trials. Apart from PET-CT, chest MRI may also become a technique of choice in the foreseeable future, given its advantage of being radiation-free.

\section{STATEMENT OF INTEREST}

A statement of interest for D. Valeyre can be found at www.erj. ersjournals.com/site/misc/statements.xhtml

\section{REFERENCES}

1 American Thoracic Society, European Respiratory Society, World Association of Sarcoidosis and Other Granulomatous Disorders. Statement on sarcoidosis. Am J Respir Crit Care Med 1999; 160: 736-755.

2 Scadding JG. Prognosis of intrathoracic sarcoidosis in England. A review of 136 cases after five years' observation. Br Med J 1961; 2: 1165-1172.

3 Baughman RP, Teirstein AS, Judson MA, et al. Clinical characteristics of patients in a case control study of sarcoidosis. Am J Respir Crit Care Med 2001; 164: 1885-1889.

4 Lynch JP 3rd, Ma YL, Koss MN, et al. Pulmonary sarcoidosis. Semin Respir Crit Care Med 2007; 28: 53-74.

5 Nunes H, Brillet PY, Valeyre D, et al. Imaging in sarcoidosis. Semin Respir Crit Care Med 2007; 28: 102-120.

6 Bein ME, Putman CE, McLoud TC, et al. A reevaluation of intrathoracic lymphadenopathy in sarcoidosis. AJR Am J Roentgenol 1978; 131: 409-415.

7 Israel HL, Lenchner G, Steiner RM. Late development of mediastinal calcification in sarcoidosis. Am Rev Respir Dis 1981; 124: 302-305.

8 Littner MR, Schachter EN, Putman CE, et al. The clinical assessment of roentgenographically atypical pulmonary sarcoidosis. Am J Med 1977; 62: 361-368.

9 Rockoff SD, Rohatgi PK. Unusual manifestations of thoracic sarcoidosis. AJR Am J Roentgenol 1985; 144: 513-528. 
10 Conant EF, Glickstein MF, Mahar P, et al. Pulmonary sarcoidosis in the older patient: conventional radiographic features. Radiology 1988; 169: 315-319.

11 Baughman RP, Shipley $R$, Desai $S$, et al. Changes in chest roentgenogram of sarcoidosis patients during a clinical trial of infliximab therapy: comparison of different methods of evaluation. Chest 2009; 136: 526-535.

12 Zappala CJ, Desai SR, Copley SJ, et al. Optimal scoring of serial change on chest radiography in sarcoidosis. Sarcoidosis Vasc Diffuse Lung Dis 2011; 28: 130-138.

13 Muers MF, Middleton WG, Gibson GJ, et al. A simple radiographic scoring method for monitoring pulmonary sarcoidosis: relations between radiographic scores, dyspnoea grade and respiratory function in the British Thoracic Society Study of Long-Term Corticosteroid Treatment. Sarcoidosis Vasc Diffuse Lung Dis 1997; 14: 46-56.

14 Winterbauer RH, Belic N, Moores KD. Clinical interpretation of bilateral hilar adenopathy. Ann Intern Med 1973; 78: 65-71.

15 Hillerdal G, Nou E, Osterman K, et al. Sarcoidosis: epidemiology and prognosis. A 15-year European study. Am Rev Respir Dis 1984; 130: 29-32.

16 Reich JM. Mortality of intrathoracic sarcoidosis in referral vs population-based settings: influence of stage, ethnicity, and corticosteroid therapy. Chest 2002; 121: 32-39.

17 Nardi A, Brillet PY, Letoumelin P, et al. Stage IV sarcoidosis: comparison of survival with the general population and causes of death. Eur Respir J 2011; 38: 1368-1373.

18 Yeager H, Rossman MD, Baughman RP, et al. Pulmonary and psychosocial findings at enrollment in the ACCESS study. Sarcoidosis Vasc Diffuse Lung Dis 2005; 22: 147-153.

19 Baughman RP, Sparkman BK, Lower EE. Six-minute walk test and health status assessment in sarcoidosis. Chest 2007; 132: 207-213.

20 Alhamad EH, Lynch JP 3rd, Martinez FJ. Pulmonary function tests in interstitial lung disease: what role do they have? Clin Chest Med 2001; 22: 715-750.

21 Harrison BD, Shaylor JM, Stokes TC, et al. Airflow limitation in sarcoidosis - a study of pulmonary function in 107 patients with newly diagnosed disease. Respir Med 1991; 85: 59-64.

22 Handa T, Nagai S, Fushimi Y, et al. Clinical and radiographic indices associated with airflow limitation in patients with sarcoidosis. Chest 2006; 130: 1851-1856.

23 Naccache JM, Lavole A, Nunes $\mathrm{H}$, et al. High-resolution computed tomographic imaging of airways in sarcoidosis patients with airflow obstruction. J Comput Assist Tomogr 2008, 32: 905-912.

24 Sharma OP, Johnson R. Airway obstruction in sarcoidosis. A study of 123 nonsmoking black American patients with sarcoidosis. Chest 1988; 94: 343-346.

25 Viskum K, Vestbo J. Vital prognosis in intrathoracic sarcoidosis with special reference to pulmonary function and radiological stage. Eur Respir J 1993; 6: 349-353.

26 Medinger AE, Khouri S, Rohatgi PK. Sarcoidosis: the value of exercise testing. Chest 2001; 120: 93-101.

27 Barros WG, Neder JA, Pereira CA, et al. Clinical, radiographic and functional predictors of pulmonary gas exchange impairment at moderate exercise in patients with sarcoidosis. Respiration 2004; 71: 367-373

28 Judson MA, Gilbert GE, Rodgers JK, et al. The utility of the chest radiograph in diagnosing exacerbations of pulmonary sarcoidosis. Respirology 2008; 13: 97-102.

29 Gibson GJ, Prescott RJ, Muers MF, et al. British Thoracic Society Sarcoidosis study: effects of long term corticosteroid treatment Thorax 1996; 51: 238-247.

30 Pietinalho A, Tukiainen P, Haahtela T, et al. Oral prednisolone followed by inhaled budesonide in newly diagnosed pulmonary sarcoidosis: a double-blind, placebo-controlled multicenter study.
Finnish Pulmonary Sarcoidosis Study Group. Chest 1999; 116: 424-431.

31 Pietinalho A, Tukiainen P, Haahtela T, et al. Early treatment of stage II sarcoidosis improves 5-year pulmonary function. Chest 2002; 121: 24-31.

32 Bradley B, Branley HM, Egan JJ, et al. Interstitial lung disease guideline: the British Thoracic Society in collaboration with the Thoracic Society of Australia and New Zealand and the Irish Thoracic Society. Thorax 2008; 63: Suppl. 5, v1-v58.

33 Beigelman-Aubry C, Hill C, Guibal A, et al. Multi-detector row $\mathrm{CT}$ and postprocessing techniques in the assessment of diffuse lung disease. Radiographics 2005; 25: 1639-1652.

34 Amis ES Jr. CT radiation dose: trending in the right direction. Radiology 2011; 261: 5-8.

35 Abehsera M, Valeyre D, Grenier P, et al. Sarcoidosis with pulmonary fibrosis: $\mathrm{CT}$ patterns and correlation with pulmonary function. AJR Am J Roentgenol 2000; 174: 1751-1757.

36 Nunes H, Humbert M, Capron F, et al. Pulmonary hypertension associated with sarcoidosis: mechanisms, haemodynamics and prognosis. Thorax 2006; 61: 68-74.

37 Lenique F, Brauner MW, Grenier P, et al. CT assessment of bronchi in sarcoidosis: endoscopic and pathologic correlations. Radiology 1995; 194: 419-423.

38 de Boer S, Milne DG, Zeng I, et al. Does CT scanning predict the likelihood of a positive transbronchial biopsy in sarcoidosis? Thorax 2009; 64: 436-439.

39 Eckardt J, Olsen KE, Jorgensen OD, et al. Minimally invasive diagnosis of sarcoidosis by EBUS when conventional diagnostics fail. Sarcoidosis Vasc Diffuse Lung Dis 2010; 27: 43-48.

40 Brauner MW, Grenier P, Mompoint D, et al. Pulmonary sarcoidosis: evaluation with high-resolution CT. Radiology 1989; 172: 467-471.

41 Leung AN, Brauner MW, Caillat-Vigneron N, et al. Sarcoidosis activity: correlation of HRCT findings with those of ${ }^{67} \mathrm{Ga}$ scanning, bronchoalveolar lavage, and serum angiotensin-converting enzyme assay. J Comput Assist Tomogr 1998; 22: 229-234.

42 Murdoch J, Muller NL. Pulmonary sarcoidosis: changes on followup CT examination. AJR Am J Roentgenol 1992; 159: 473-477.

43 Oberstein A, von Zitzewitz H, Schweden F, et al. Non invasive evaluation of the inflammatory activity in sarcoidosis with highresolution computed tomography. Sarcoidosis Vasc Diffuse Lung Dis 1997; 14: 65-72.

44 Remy-Jardin M, Giraud F, Remy J, et al. Pulmonary sarcoidosis: role of $\mathrm{CT}$ in the evaluation of disease activity and functional impairment and in prognosis assessment. Radiology 1994; 191 675-680.

45 Akira M, Kozuka T, Inoue $Y$, et al. Long-term follow-up CT scan evaluation in patients with pulmonary sarcoidosis. Chest 2005; 127: 185-191.

46 Bergin CJ, Bell DY, Coblentz CL, et al. Sarcoidosis: correlation of pulmonary parenchymal pattern at CT with results of pulmonary function tests. Radiology 1989; 171: 619-624.

47 Davies CW, Tasker AD, Padley SP, et al. Air trapping in sarcoidosis on computed tomography: correlation with lung function. Clin Radiol 2000; 55: 217-221.

48 Drent M, De Vries J, Lenters M, et al. Sarcoidosis: assessment of disease severity using HRCT. Eur Radiol 2003; 13: 2462-2471.

49 Handa $T$, Nagai S, Miki S, et al. Incidence of pulmonary hypertension and its clinical relevance in patients with sarcoidosis. Chest 2006; 129: 1246-1252.

50 Hansell DM, Milne DG, Wilsher ML, et al. Pulmonary sarcoidosis: morphologic associations of airflow obstruction at thinsection CT. Radiology 1998; 209: 697-704.

51 Lopes AJ, de Menezes SL, Dias CM, et al. Comparison between cardiopulmonary exercise testing parameters and computed tomography findings in patients with thoracic sarcoidosis. Lung 2011; 189: 425-431. 
52 Magkanas E, Voloudaki A, Bouros D, et al. Pulmonary sarcoidosis. Correlation of expiratory high-resolution CT findings with inspiratory patterns and pulmonary function tests. Acta Radiol 2001; 42: 494-501.

53 Muller NL, Mawson JB, Mathieson JR, et al. Sarcoidosis: correlation of extent of disease at CT with clinical, functional, and radiographic findings. Radiology 1989; 171: 613-618.

54 Terasaki H, Fujimoto K, Muller NL, et al. Pulmonary sarcoidosis: comparison of findings of inspiratory and expiratory highresolution $\mathrm{CT}$ and pulmonary function tests between smokers and nonsmokers. AJR Am J Roentgenol 2005; 185: 333-338.

55 Criado E, Sanchez M, Ramirez J, et al. Pulmonary sarcoidosis: typical and atypical manifestations at high-resolution CT with pathologic correlation. Radiographics, 30: 1567-1586.

56 Hansell DM, Bankier AA, MacMahon H, et al. Fleischner Society: glossary of terms for thoracic imaging. Radiology 2008; 246: 697-722.

57 Sider L, Horton ES Jr. Hilar and mediastinal adenopathy in sarcoidosis as detected by computed tomography. J Thorac Imaging 1990; 5: 77-80.

58 Gawne-Cain ML, Hansell DM. The pattern and distribution of calcified mediastinal lymph nodes in sarcoidosis and tuberculosis: a CT study. Clin Radiol 1996; 51: 263-267.

59 Niimi H, Kang EY, Kwong JS, et al. CT of chronic infiltrative lung disease: prevalence of mediastinal lymphadenopathy. J Comput Assist Tomogr 1996; 20: 305-308.

60 Patil SN, Levin DL. Distribution of thoracic lymphadenopathy in sarcoidosis using computed tomography. J Thorac Imaging 1999; 14: 114-117.

61 Polychronopoulos VS, Prakash UB. Airway involvement in sarcoidosis. Chest 2009; 136: 1371-1380.

62 Morawiec E, Hachulla-Lemaire AL, Chabrol J, et al. Venoatrial compression by lymphadenopathy in sarcoidosis. Eur Respir J 2010; 35: 1188-1191.

63 Yangui F, Battesti JP, Valeyre D, et al. Fibrosing mediastinitis as a rare mechanism of pulmonary oedema in sarcoidosis. Eur Respir J 2010; 35: 455-456.

64 Narayan D, Brown L, Thayer JO. Surgical management of superior vena caval syndrome in sarcoidosis. Ann Thorac Surg 1998; 66: 946-948.

65 Cappell MS. Endoscopic, radiographic, and manometric findings in dysphagia associated with sarcoid due to extrinsic esophageal compression from subcarinal lymphadenopathy. Am J Gastroenterol 1995; 90: 489-492.

66 Tobias JK, Santiago SM, Williams AJ. Sarcoidosis as a cause of left recurrent laryngeal nerve palsy. Arch Otolaryngol Head Neck Surg 1990; 116: 971-972.

67 Jarman PR, Whyte MK, Sabroe I, et al. Sarcoidosis presenting with chylothorax. Thorax 1995; 50: 1324-1325.

68 Nishimura K, Itoh $\mathrm{H}$, Kitaichi M, et al. Pulmonary sarcoidosis: correlation of CT and histopathologic findings. Radiology 1993; 189: 105-109.

69 Brauner M, Dumas JL, Beigelman C. Imagerie de la sarcoïdose pulmonaire. [Imaging of pulmonary sarcoidosis.] Ann Radiol (Paris) 1994; 37: 216-221.

70 Hamper UM, Fishman EK, Khouri NF, et al. Typical and atypical CT manifestations of pulmonary sarcoidosis. J Comput Assist Tomogr 1986; 10: 928-936.

71 Honda $\mathrm{O}$, Johkoh $\mathrm{T}$, Ichikado $\mathrm{K}$, et al. Comparison of high resolution CT findings of sarcoidosis, lymphoma, and lymphangitic carcinoma: is there any difference of involved interstitium? J Comput Assist Tomogr 1999; 23: 374-379.

72 Gruden JF, Webb WR, Naidich DP, et al. Multinodular disease: anatomic localization at thin-section CT - multireader evaluation of a simple algorithm. Radiology 1999; 210: 711-720.

73 Hours S, Nunes H, Kambouchner M, et al. Pulmonary cavitary sarcoidosis: clinico-radiologic characteristics and natural history of a rare form of sarcoidosis. Medicine (Baltimore) 2008; 87: 142-151.

74 Malaisamy S, Dalal B, Bimenyuy C, et al. The clinical and radiologic features of nodular pulmonary sarcoidosis. Lung 2009; 187: 9-15.

75 Nakatsu M, Hatabu H, Morikawa K, et al. Large coalescent parenchymal nodules in pulmonary sarcoidosis: "sarcoid galaxy" sign. AJR Am J Roentgenol 2002; 178: 1389-1393.

76 Brauner MW, Lenoir S, Grenier P, et al. Pulmonary sarcoidosis: CT assessment of lesion reversibility. Radiology 1992; 182 349-354.

77 Johkoh T, Ikezoe J, Takeuchi N, et al. CT findings in "pseudoalveolar" sarcoidosis. J Comput Assist Tomogr 1992; 16: 904-907.

78 Judson MA, Uflacker R. Treatment of a solitary pulmonary sarcoidosis mass by CT-guided direct intralesional injection of corticosteroid. Chest 2001; 120: 316-317.

79 Quaden C, Tillie-Leblond I, Delobbe A, et al. Necrotising sarcoid granulomatosis: clinical, functional, endoscopical and radiographical evaluations. Eur Respir J 2005; 26: 778-785.

80 Froudarakis ME, Bouros D, Voloudaki A, et al. Pneumothorax as a first manifestation of sarcoidosis. Chest 1997; 112: 278-280.

81 Marchiori E, Zanetti G, Barreto MM, et al. Atypical distribution of small nodules on high resolution CT studies: patterns and differentials. Respir Med, 105: 1263-1267.

82 Herraez Ortega I, Alonso Orcajo N, Lopez Gonzalez L. El "cúmulo sarcoideo". Un nuevo signo en tomografía computarizada de tórax de alta resolución. [The "sarcoid cluster sign". A new sign in high resolution chest CT.] Radiologia 2009; 51: 495-499.

83 Martin SG, Kronek LP, Valeyre D, et al. High-resolution computed tomography to differentiate chronic diffuse interstitial lung diseases with predominant ground-glass pattern using logical analysis of data. Eur Radiol 2010; 20: 1297-1310.

84 Padley SP, Padhani AR, Nicholson A, et al. Pulmonary sarcoidosis mimicking cryptogenic fibrosing alveolitis on CT. Clin Radiol 1996; 51: 807-810.

85 Aisner SC, Albin RJ. Diffuse interstitial pneumonitis and fibrosis in sarcoidosis. Chest 1988; 94: 193-195.

86 Nobata K, Kasai T, Fujimura M, et al. Pulmonary sarcoidosis with usual interstitial pneumonia distributed predominantly in the lower lung fields. Intern Med 2006; 45: 359-362.

87 Shigemitsu H, Oblad JM, Sharma OP, et al. Chronic interstitial pneumonitis in end-stage sarcoidosis. Eur Respir J 2010; 35: 695697.

88 Bartz RR, Stern EJ. Airways obstruction in patients with sarcoidosis: expiratory CT scan findings. J Thorac Imaging 2000; 15: 285-289.

89 Fazzi P, Sbragia P, Solfanelli S, et al. Functional significance of the decreased attenuation sign on expiratory $\mathrm{CT}$ in pulmonary sarcoidosis: report of four cases. Chest 2001; 119: 1270-1274.

90 Gleeson FV, Traill ZC, Hansell DM. Evidence of expiratory CT scans of small-airway obstruction in sarcoidosis. AJR Am J Roentgenol 1996; 166: 1052-1054.

91 Nishino $\mathrm{M}$, Kuroki $\mathrm{M}$, Roberts $\mathrm{DH}$, et al. Bronchomalacia in sarcoidosis: evaluation on volumetric expiratory high-resolution CT of the lung. Acad Radiol 2005; 12: 596-601.

92 Huggins JT, Doelken P, Sahn SA, et al. Pleural effusions in a series of 181 outpatients with sarcoidosis. Chest 2006; 129: 1599-1604.

93 Szwarcberg JB, Glajchen N, Teirstein AS. Pleural involvement in chronic sarcoidosis detected by thoracic CT scanning. Sarcoidosis Vasc Diffuse Lung Dis 2005; 22: 58-62.

94 Harada T, Nabeshima K, Matsumoto T, et al. Histological findings of the computed tomography halo in pulmonary sarcoidosis. Eur Respir J 2009; 34: 281-283.

95 Marten K, Rummeny EJ, Engelke C. The CT halo: a new sign in active pulmonary sarcoidosis. British J Radiol 2004; 77: 1042-1045. 
96 Marlow TJ, Krapiva PI, Schabel SI, et al. The "fairy ring": a new radiographic finding in sarcoidosis. Chest 1999; 115: 275-276.

97 Lee YR, Choi YW, Lee KJ, et al. CT halo sign: the spectrum of pulmonary diseases. Br J Radiol 2005; 78: 862-865.

98 Grenier P, Chevret S, Beigelman C, et al. Chronic diffuse infiltrative lung disease: determination of the diagnostic value of clinical data, chest radiography, and CT and Bayesian analysis. Radiology 1994; 191: 383-390.

99 Mana J, Teirstein AS, Mendelson DS, et al. Excessive thoracic computed tomographic scanning in sarcoidosis. Thorax 1995; 50: 1264-1266.

100 Kaiser PK, Lowder CY, Sullivan P, et al. Chest computerized tomography in the evaluation of uveitis in elderly women. Am J Ophthalmol 2002; 133: 499-505.

101 Kosmorsky GS, Meisler DM, Rice TW, et al. Chest computed tomography and mediastinoscopy in the diagnosis of sarcoidosisassociated uveitis. Am J Ophthalmol 1998; 126: 132-134.

102 Klein JS, Johnson A, Watson E, et al. CT-guided transthoracic needle biopsy in the diagnosis of sarcoidosis. J Thorac Imaging 2009; 24: 23-30.

103 Remy-Jardin M, Giraud F, Remy J, et al. Importance of groundglass attenuation in chronic diffuse infiltrative lung disease: pathologic-CT correlation. Radiology 1993; 189: 693-638

104 Pena TA, Soubani AO, Samavati L. Aspergillus lung disease in patients with sarcoidosis: a case series and review of the literature. Lung 2011; 189: 167-172.

105 Hoffstein V, Ranganathan N, Mullen JB. Sarcoidosis simulating pulmonary veno-occlusive disease. Am Rev Respir Dis 1986; 134 809-811.

106 Devaraj A, Wells AU, Meister MG, et al. The effect of diffuse pulmonary fibrosis on the reliability of CT signs of pulmonary hypertension. Radiology 2008; 249: 1042-1049.
107 Crawshaw AP, Wotton CJ, Yeates DG, et al. Evidence for association between sarcoidosis and pulmonary embolism from 35-year record linkage study. Thorax 2011; 66: 447-448.

108 Chambellan A, Turbie P, Nunes H, et al. Endoluminal stenosis of proximal bronchi in sarcoidosis: bronchoscopy, function, and evolution. Chest 2005; 127: 472-481.

109 Naidich DP, Lee JJ, Garay SM, et al. Comparison of CT and fiberoptic bronchoscopy in the evaluation of bronchial disease. AJR Am J Roentgenol 1987; 148: 1-7.

110 Kauczor HU, Ley-Zaporozhan J, Ley S. Imaging of pulmonary pathologies: focus on magnetic resonance imaging. Proc Am Thorac Soc 2009; 6: 458-463.

111 Craig DA, Colletti PM, Ratto D, et al. MRI findings in pulmonary sarcoidosis. Magn Reson Imaging 1988; 6: 567-573.

112 McFadden RG, Carr TJ, Wood TE. Proton magnetic resonance imaging to stage activity of interstitial lung disease. Chest 1987; 92: 31-39.

113 Mendelson DS, Gray CE, Teirstein AS. Magnetic resonance findings in sarcoidosis of the thorax. Magn Reson Imaging 1992; 10: 523-529.

114 Muller NL, Mayo JR, Zwirewich CV. Value of MR imaging in the evaluation of chronic infiltrative lung diseases: comparison with CT. AJR Am J Roentgenol 1992; 158: 1205-1209.

115 Primack SL, Mayo JR, Hartman TE, et al. MRI of infiltrative lung disease: comparison with pathologic findings. J Comput Assist Tomogr 1994; 18: 233-238.

116 Gaeta M, Blandino A, Scribano E, et al. Chronic infiltrative lung diseases: value of gadolinium-enhanced MRI in the evaluation of disease activity - early report. Chest 2000; 117: 1173-1178.

117 Henzler T, Schmid-Bindert G, Schoenberg SO, et al. Diffusion and perfusion MRI of the lung and mediastinum. Eur J Radiol 2010; 76: 329-336. 